\title{
ANEMIA E ALIMENTAÇÃO NO PRRIMIEIRO ANO DE VIDA
}

Tese apresentada à Faculdade de Saúde Pública da Universidade de São Paulo, Departamento de Nutrição, para obtenção do título de Doutor em Saúde Pública.

Orientadora: Prof. Dra. Sophia Cornbluth Szarfarc

São Paulo

1994 


\section{DEDICATÓRIA}

Aos meus pais:

Alberto e Maria Elisa

Ao meu marido:

José Maria

Aos meus filhos:

Cláudio Luís, Adriana

e Fernanda (em memória). 


\section{AGRADECIMENTOS}

1- À Professora Doutora Sophia Cornbluth Szarfarc, pela orientação, estímulo e dedicação ao longo do trabalho.

2- Ao Professor Doutor José Maria Pacheco de Souza, pela assessoria em estatística e micro computação e pelo estímulo constante.

3- À Técnica de Laboratório Maria Silvéria Emígdio, pelo treinamento dos atendentes de saúde dos Centros de Saúde.

4- À Raquel Helena Bonafé, Regina Célia Miguel, Rita de Cassia Ribeiro da Silva, Rosana Farah Simony, Vera Martha Bonafé e Vera Sílvia Frangella, pela realização das entrevistas.

5- A Marli Oliveira Couto e Ricardo Rodrigues Teixeira pela colheita de sangue no Centro de Saúde do Butantã.

6- À Ana Lúcia Lumazine de Moraes e à Rita de Cássia Ribeiro da Silva pela colheita de sangue, respectivamente, nos Centros de Saúde Geraldo de Paula Souza e da Escola Paulista de Medicina.

7- Aos diretores e funcionários dos centros de Saúde Geraldo de Paula Souza, Samuel Barnsley Pessoa, da Barra Funda, da Escola Paulista de Medicina e do Laboratório do Centro de Saúde Geraldo de Paula Souza, pela atenção e colaboração durante o período do levantamento de dados.

8- A Adriana de Souza Villela, pela revisão do texto.

9- Ao Júlio César Maiello Villela, pela formatação do texto e tabelas. 
10- À Regina Rodrigues, pela elaboração do formulário.

11-.A Bibliotecária Angela Maria Belloni Cuenca, pela revisão das referências bibliográficas.

12- Ao Conselho Nacional de Desenvolvimento Científico e Tecnológico - CNPq, pelo auxílio-pesquisa concedido em 1991 e pela bolsa concedida em 1992 e 1993.

13- À Coordenadoria de Aperfeiçoamento de Pessoal de Ensino Superior - CAPES, por possibilitar, mediante bolsa, 0 acesso à bibliografia especializada.

14- Aos colegas, técnicos e funcionários administrativos do Departamento de Nutrição, pelo apoio e incentivo.

15- A todos que, direta ou indiretamente, contribuíram para a realização deste trabalho. 


\section{RESUMO}

o presente trabalho teve por objetivo verificar a possível associação entre alimentação no primeiro ano de vida e anemia ferropriva. Estudou-se uma amostra de 317 crianças com até 12 meses de idade, matriculadas e freqüentando quatro centros de Saúde Escola do municipio de são Paulo.

As informações sobre a alimentação foram obtidas pelo método de inquérito recordatório, em entrevista com as mães das crianças, na ocasião da consulta ou da vacinação. A presença de anemia foi verificada pela concentração de hemoglobina, determinada pelo método da cianometahemoglobina. Utilizou-se o critério recomendado pela organização Mundial de Saúde (OMS) para diagnóstico da anemia, verificando-se a prevalência de 14,5\% entre toda a população e $22,4 \%$ entre as crianças maiores de 180 dias.

As associações entre anemia e duração do aleitamento materno exclusivo, idade de introdução de alimentos não lácteos e frequiência de consumo de alimentos fontes de ferro e/ou potenciadores da sua absorção não foram significantes. A ausência do aleitamento materno, até pelo menos 4 meses, associou-se à anemia. Nessa faixa etária encontraram-se 26,90 de anêmicas entre as crianças que tomavam outros leites e 8,6\% entre as que só recebiam leite materno. A anemia não se associou às variáveis sócioeconômicas estudadas: escolaridade do pai, da mãe e renda familiar. 


\section{SUMMARY}

This study was made to find out the possible association between the diet in the first year of life and iron deficiency anemia. A sample of 317 infants aged 0-12 months was studied in four school health centers in the city of são Paulo.

The informations about diet were obtained by the recordatory survey method, in interviews with the infant's mothers. The presence of anemia was verified by hemoglobin concentration, using the cianometahemoglobin method. The criteria recommended by the World Health Organization (WHO) was utilized for the diagnostic of anemia. The prevalence of $14,5 \frac{0}{\circ}$ was found in all the population and $22,4 \%$ in infants aged more than 180 days.

The associations between anemia and time of exclusively breast-feeding, and age of introduction of other foods and/or eating foods which enhance iron absorption were not significants. The absence of breast-feeding, until at least 4 months, were associated with anemia. In this age were found $26,9 \%$ of anemics among infants receiving others milks and $8,6 \frac{\circ}{\circ}$ among those receiving only breast milk. Anemia was not associated with socioeconomic variables: parents education levels and familiar income. 


\section{ÍNDICE}

Página

1 - INTRODUÇÃO.

2 - OBJETIVOS.

3 - MATERIAL E MÉtodos. .8

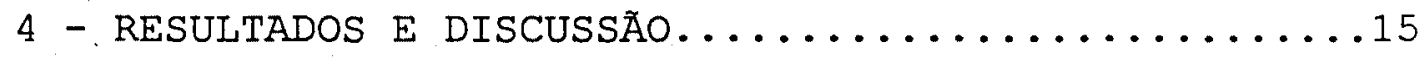

5 - CONCLUSÕES. 65

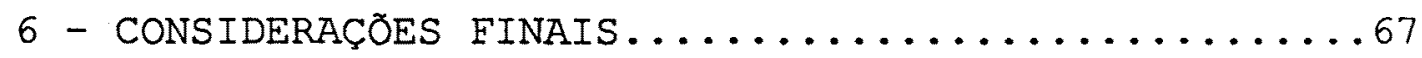

7 - REFERÊNCIAS BIBLIOGRÁFICAS. .70

8 - ANEXO. 


\section{INTRODUÇÃO}

A anemia ferropriva ocorre como resultado de um desequilíbrio no balanço entre a quantidade de ferro biologicamente disponível e a necessidade orgânical3 e, segundo a Organização Mundial de Saúde-OMS, atinge $30 \%$ da população mundial ${ }^{9}$.

Em saúde pública, o termo anemia refere-se à anemia ferropriva, visto que a deficiência de ferro é, sem dúvida, a causa mais comum da doença ${ }^{21}$.

A prevalência da anemia é maior em países em desenvolvimento que naqueles altamente industrializados ${ }^{14}$. Dados da OMS mostram que as populações da África e do sul da Ásia apresentam as maiores prevalências. Com exceção de adultos do sexo masculino, a prevalência, nessas regiões, está acima de 40\%. Na América Latina, ela é mais baixa, variando de 13\%, entre homens adultos, a 30\% entre gestantes ${ }^{9}$.

Esses dados sugerem que existe uma associação entre anemia e nível de desenvolvimento sócio-econômico da população. Entretanto, no Brasil, vários estudos mostram que, dentro de um mesmo grupo populacional, nem sempre a deficiência está associada a variáveis indicadoras da situação sócio-econômica, como a renda $16,31,45,50$.

As crianças, nos primeiros anos de vida, e as gestantes constituem os grupos mais vulneráveis à anemia. Para elas, a OMS apresenta prevalência estimada de $43 \%$ e 51\%, respectivamente 9,10 . Vários estudos, realizados em diversas regiões do mundo, corroboram essa estimativa. 
Em Cuba, verificaram-se, em investigação realizada na cidade de Havana, 45\% de anêmicos entre crianças com 6 meses a 1 ano de idade ${ }^{73}$. Em estudo realizado no Canadá, nos cinco distritos de saúde mais pobres de Montreal, encontraram-se $27 \%$ de anêmicos, entre 218 crianças com idades entre 10 e 14 meses $^{24}$. No Uruguai, em 100 crianças com idades entre 9 e 36 meses que freqüentavam a clínica pediátrica de um hospital em Montevideo, encontraram-se 59 crianças com niveis de hemoglobina abaixo do limite de normalidade $^{43}$.

No Brasil, os estudos sobre anemia não são muitos, e a maioria deles se refere a grupos populacionais restritos. Os resultados encontrados permitem, entretanto, supor a existência de elevada prevalência em nosso meio16,31,45,47,50,72.

Em 1973-74, Sigulem encontrou, em crianças menores de 5 anos do município de São Paulo, 22,7\% de anêmicos ${ }^{50}$. Em 1985 foram observadas, em dois serviços de saúde de Recife, as prevalências de $28,3 \%$ e 55,1\%, em crianças do mesmo grupo etário45. Em centro de saúde de Itapetininga, interior do estado de são Paulo, em 1987, encontraram-se 50,0\% de anêmicos entre meninos com idades entre 6 e 11 meses e 52,2\% entre meninas da mesma idade ${ }^{71}$.

Em 1984-85, no município de São Paulo, foi realizado um amplo estudo epidemiológico sobre condições de saúde e nutrição na infância. Os autores encontraram, em crianças de 0 a 60 meses, 35\% de anêmicas, das quais 14,7\% apresentavam anemia severa. As maiores prevalências foram encontradas entre crianças de 6 a 24 meses. A partir dessa idade, a ocorrência da anemia, inclusive dos casos mais severos, declinava de forma linear ${ }^{31}$.

Comparando-se os resultados dessa pesquisa com os de Sigulem50, foi evidenciado importante aumento da prevalência dessa deficiência nutricional: mais de $50 \%$ em relação à totalidade dos casos e mais de $100 \%$ em relação àqueles mais severos ${ }^{31}$. 
Essa situação é preocupante, pois sabe-se que a anemia interfere nos processos de crescimento e desenvolvimento da criança, com algumas consequiencias que devem ser salientadas: prejuízo no desenvolvimento mental e motor; prejuízo no desenvolvimento da linguagem; alterações comportamentais e psicológicas, como falta de atenção, fadiga, insegurança; diminuição da atividade física12,26,75,76. São descritas, ainda, alterações metabólicas diversas, alterações de pele e mucosas, comprometimento dos sistemas digestivo e imunológico, constituindo a sindrome denominada enfermidade ferropriva67.

É fundamental o conhecimento da etiologia da anemia na criança, particularmente no lactente, visto que as maiores prevalências da deficiência ocorrem até os dois anos de idade ${ }^{31}$.

Os fatores envolvidos nessa etiologia e que determinam as necessidades de ferro no lactente são: as reservas de ferro ao nascer, a velocidade de crescimento e as perdas do mineral44,56,57.

A quantidade de ferro na criança ao nascer independe do estado da mãe em relação ao mineral, com exceção de casos de deficiências maternas muito graves. Deve-se levar em conta, no entanto, que a deficiência de ferro da mãe pode ser acompanhada de atraso no crescimento fetal e/ou parto prematuro, exercendo, portanto, uma influência indireta nas reservas do nutriente no recémnascido17,33,52,56,57. Baixas reservas de ferro ao nascer, determinando aparecimento precoce de anemia, podem estar associadas a situações anormais como as hemorragias perinatais $37,66,74$.

Durante a vida intra-uterina, o feto acumula ferro em quantidade proporcional a seu aumento de peso. A criança de termo, ao nascer, tem cerca de $75 \mathrm{mg}$ de ferro por quilo de peso, dos quais dois terços se encontram sob a forma de hemoglobina ${ }^{37}$.

Nos primeiros dois meses de vida ocorre uma queda acentuada na concentração de hemoglobina, que alcança os valores mais 
baixos entre 8 e 12 semanas (ao redor de $11 \mathrm{~g} / \mathrm{dl}$ ). Essa queda é conhecida como "anemia fisiológica do lactente", não sendo evitada por qualquer medida preventiva e não sendo acompanhada de qualquer anomalia 37 .

O nível de hemoglobina será tanto mais baixo quanto menor 0 peso de nascimento. Em crianças prematuras, com pesos entre 1000 e 1500g, os niveis mínimos de concentração de hemoglobina se situam 2 a $3 g$ abaixo dos observados no recém-nascido de termo 59 .

As reservas de ferro acumuladas pelo feto são mobilizadas, a partir do nascimento, para suprir as necessidades do nutriente, impostas pelo crescimento e pela reposição das perdas através da pele e das fezes, até aproximadamente 6 meses $5,9,44$.

Com isso, não seria esperada grande incidência de anemia até essa idade. No entanto, em crianças do município de São Paulo, foram verificados valores médios de concentração de hemoglobina inferiores àqueles encontrados em população normal, já a partir de 2 meses $^{31}$.

Entre 4 e 6 meses, ocorre o esgotamento das reservas de ferro e a alimentação passa a ter papel preponderante no atendimento das necessidades do nutriente ${ }^{57}$.

A velocidade de crescimento da criança, no seu primeiro ano, é maior que em qualquer outra fase da vida. Nesse período, ela triplica seu peso de nascimento, e a sua necessidade de ferro por quilo de peso corporal é elevada - $120 \mu \mathrm{g} / \mathrm{kg} / \mathrm{dia}$ - e maior que a do adulto - $18 \mu \mathrm{g} / \mathrm{kg} / \mathrm{dia}^{57}$.

Até 6 meses de idade, quando a criança recebe, com exclusividade, o leite materno, a demanda de ferro pode ser atendi-

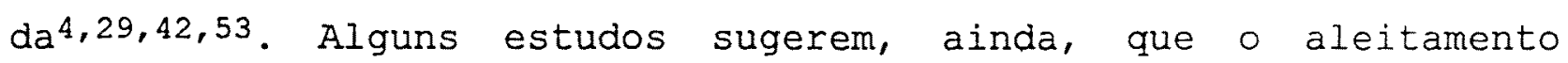
materno exclusivo é suficiente para manter um estado nutricional 
adequado em relação ao ferro durante, praticamente, todo o primeiro ano de vida15,27,29,40.

Essa propriedade do leite materno se deve menos à concentração de ferro, que é baixa $(0,1$ a $1,6 \mathrm{mg} / 1)$, e muito mais à sua biodisponibilidade elevada (cerca de 50\%) 8,25,41. Sabe-se, entretanto, que esta diminui em até $80 \%$, quando outros alimentos passam a ser ingeridos pelo lactente ${ }^{6,42}$.

Resultados verificados em alguns estudos permitem aventar a hipótese de que a existência de anemia no primeiro ano de vida tenha como fator causal, entre outros, o desmame precoce ${ }^{68}$. 0 leite fluido, geralmente utilizado na substituição do leite materno, tem baixa biodisponibilidade de ferro e pode acarretar microhemorragias intestinais, sobretudo na criança de pouca idade $36,38,39,77$.

Outro fator que concorre para o aparecimento da anemia é a relativa monotonia da dieta do lactente ${ }^{57}$. Em estudo realizado no município de São Paulo, com crianças menores de 60 meses, verificou-se baixo consumo de ferro em todas as idades, com apenas 10\% das crianças tendo ingestões diárias acima de $10 \mathrm{mg}^{47}$. Nessa mesma população, estudou-se a prática alimentar no primeiro ano de vida, sendo verificado baixo consumo de alimentos fontes de ferro como carnes, feijão, hortaliças de folha elou alimentos potenciadores da absorção do mineral, como frutas ricas em vitamina C. 0 leite integral com açúcar era bastante consumido, enquanto a ingestão de fórmulas (leites modificados) e alimentos enriquecidos, indicados para prevenção da deficiência, mostrou-se praticamente inexistente 30,64 . Vale destacar que, entre os alimentos apontados, a carne tem papel especial em relação ao fornecimento de ferro, por ser fonte deste, por conter ferro heme - de elevada biodisponibilidade - e, da mesma forma que a vitamina $c$, por implementar a absorção de ferro não heme ${ }^{57}$. 
Em 1980, Szarfarc e cols. verificaram a orientação pediátrica em relação à dieta de lactentes, em áreas urbanas não metropolitanas do estado de São Paulo, com o objetivo de estimar o aporte de ferro da dieta. Foi constatado que os alimentos mais recomendados para preparar a refeição de sal eram os legumes, tubérculos e cereais, todos pobres em ferro63.

É possivel que a prática alimentar seja o determinante principal da anemia do lactente. Assim, considerando que essa deficiência representa importante problema de saúde pública - quer pela elevada frequiencia e precocidade com que ocorre, quer pelos efeitos deletérios que acarreta à qualidade de vida62,64 -, é importante $\circ$ conhecimento da dieta oferecida ao lactente para a escolha de intervenções adequadas para controle da deficiência de ferro.

Assim, para atingir os objetivos desta pesquisa, foram estudadas a prática alimentar no primeiro ano de vida e sua relação com a anemia. 


\section{OBJETIVOS}

2.1.GERAL

- Verificar a prática alimentar no primeiro ano de vida e sua relação com a anemia.

2.2.ESPECÍFICOS

-Identificar a prática alimentar no primeiro ano de vida.

-Quantificar a prevalência da anemia.

-Verificar a relação entre anemia e:

. idade e peso ao nascer;

.duração do aleitamento materno;

.introdução de diferentes tipos de leite;

- introdução de alimentos não lácteos;

- frequiência de consumo de alimentos fontes de ferro;

- frequiência de consumo de alimentos potenciadores da absorção de ferro não heme;

. indicadores sócio-econômicos. 


\section{MATERIAI E MÉTODOS}

3.1.DESCRIÇÃO DOS LOCAIS DE ESTUDO E DA AMOSTRA

O estudo foi realizado em quatro Centros de Saúde Escola (CSEs), no município de São Paulo: Centro de Saúde Escola Geraldo de Paula Souza, da Faculdade de Saúde Pública da Universidade de São Paulo, que atende moradores de Vila Madalena e Jardim América; Centro de Saúde Escola Samuel Barnsley Pessoa, da Universidade de São Paulo, que atende à população do Butantã; Centro de Saúde Escola da Barra Funda, da Faculdade de Ciências Médicas da Santa Casa, que atende residentes da Barra Funda, e Centro de Saúde Escola da Escola Paulista de Medicina, que atende população de Vila Clementino e Vila Mariana.

Os CSEs, além da demanda de residentes das áreas, prestam atendimento, também, a escolas e creches dessas regiões. Com exceção do CSE da Barra Funda, que tem considerável proporção da população vivendo em cortiços, os demais têm favelas de diferentes portes em suas áreas.

A população é atendida nos programas: saúde da criança, do adolescente, do adulto, da mulher, do idoso, saúde mental e saúde bucal, além de especialidades, como dermatologia sanitária e tisiologia.

Nos CSEs da Barra Funda, do Butantã e da Escola Paulista de Medicina, parte do atendimento médico é feito por alunos dos cursos de medicina, respectivamente da Santa Casa, Universidade de São Paulo e da Escola Paulista de Medicina. Os CSEs proporcionam, também, estágios e aprimoramento nas áreas de enfermagem, nutrição, terapia ocupacional, psicologia e serviço social. 
Embora sabendo-se que as maiores prevalências de anemia ocorrem no segundo ano de vida9,10,31, decidiu-se trabalhar com crianças até 1 ano de idade, devido à importância da alimentação do lactente, em particular do aleitamento materno, na etiologia da doença. Vale destacar, que nessa idade, devem ser desenvolvidos os programas de intervenção que vão, provavelmente, diminuir a prevalência da doença em crianças maiores de 1 ano. Considerou-se, ainda, que a demanda característica dos serviços de saúde é constituida, principalmente, por crianças até 1 ano de idade.

Os serviços de saúde, especialmente os CSEs, por meio do programa de saúde da criança, desenvolveram bom nível de conscientização nas mães em relação à necessidade de passar a freqüentar o serviço, o mais cedo possível após o nascimento da criança, para controle do crescimento, vacinas, participação em grupos de incentivo ao aleitamento materno, de orientação alimentar, de cuidados higiênicos, ou mesmo para receber suplementação de leite. Após 1 ano de idade, a criança passa a freqüentar os centros de saúde, quase exclusivamente, quando a mãe julga que ela está doente, conforme verificado em trabalhos anteriores55,65. Esse fato dificulta sobremaneira o acesso a essa criança.

Decidiu-se realizar o presente estudo em CSEs por se considerar a população, que constitui a demanda desses serviços, mais acessivel, por ser bastante trabalhada pelos profissionais que neles atuam desenvolvendo grupos, cursos, estudos e pesquisas. Possuem, ainda, infra-estrutura que permite o desenvolvimento de pesquisas com maior facilidade.

o estudo foi desenvolvido de abril a outubro de 1991. Nesse período, foram selecionadas 317 crianças, por meio dos seguintes critérios:

1-estar matriculada em um dos CSEs;

2-estar agendada para consulta de puericultura ou vacina, no momento da entrevista;

3-ter até 12 meses de idade. 


\subsection{LEVANTAMENTO DOS DADOS}

- levantamento de dados foi feito por quatro entrevistadores, previamente treinados, que permaneciam nos CSEs nos dias de atendimento. Inicialmente, eles selecionavam as crianças que atendiam aos critérios determinados. Em seguida, explicavam a pesquisa para a mãe ou responsável e, obtendo seu consentimento para a participação da criança, a entrevista era realizada.

Na mesma ocasião, atendentes de saúde do próprio CSE, especialmente treinados, faziam a colheita de $20 \mu 1$ de sangue, por puntura do pé, diretamente com a pipeta de Sahli, para dosagem de hemoglobina ( $\mathrm{Hb})$, pelo método da cianometahemoglobina22. As amostras colhidas eram levadas, no mesmo dia, para o Laboratório de Bioquímica do Departamento de Nutrição da Faculdade de Saúde Pública da Universidade de São Paulo. Os dados obtidos na entrevista eram coletados em formulário pré-testado (anexo 1), ao qual eram anexados os resultados do exame bioquimico. Recorria-se ao registro de dados dos CSEs quando a mãe não sabia informar peso e/ou altura da criança.

As variáveis sexo, idade, peso ao nascer, idade e escolaridade dos pais, bem como renda familiar foram utilizadas para descrever a população. A prática alimentar foi identificada por meio das variáveis: duração do aleitamento materno exclusivo, idade de introdução de outros tipos de leite (fluído, em pó integral, formulado), idade de introdução de alimentos não lácteos e frequiência de consumo de alimentos fontes de ferro e/ou potenciadores da absorção de ferro não heme. A freqüência semanal de consumo dos alimentos, nos trinta dias anteriores à entrevista, foi obtida pelo método recordatório de inquérito alimentar. Para verificar a consistência das informações foi feito, ainda, levantamento da alimentação do dia anterior, pelo método recordatório de 24 horas. 
3.3.DEFINIÇÃO DE VARIÁVEIS

As variáveis que caracterizaram a situação da criança em relação à alimentação e aquelas utilizadas como indicadores sócioeconômicos são definidas a seguir:

- AME - Aleitamento materno exclusivo:

situação em que o único alimento ingerido era o leite materno.

- AAE - Aleitamento artificial exclusivo:

quando o único alimento ingerido era qualquer tipo de leite que não o materno.

- AM - Aleitamento misto:

quando eram ingeridos leite materno e qualquer outro tipo de leite.

- MNL - Aleitamento materno mais alimentos não lácteos: quando o leite ingerido era o materno, e a criança já recebia outros alimentos.

- ANL - Aleitamento artificial mais alimentos não lácteos:

quando o leite ingerido não era o materno, e a criança já recebia outros alimentos.

- MANL - Aleitamento misto mais alimentos não lácteos: quando a criança recebia leite materno, outro tipo de leite e outros alimentos.

- Número de refeições por dia:

definiu-se como refeição o conjunto de alimentos ingeridos a um só tempo, no qual o leite não era o principal. 
- Alimentos não lácteos:

consideraram-se todos os alimentos da dieta da criança, com exceção do leite.

Para a análise da relação entre anemia e introducão e frequiencia de consumo, foram destacados os seguintes alimentos: frutas, carnes, feijão e hortaliças (somente as de folhas), por serem fontes de ferro e/ou potenciadores da absorção do ferro não heme. Incluiu-se a gema de ovo, por ter sido considerada como fonte de ferro, por longo tempo.

- Escolaridade:

Foram consideradas as seguintes categorias:

- nenhuma: nunca frequientou escola;

baixa: curso primário incompleto;

- média baixa: curso primário completo a gina-

sial incompleto;

- média alta: curso ginasial completo a colegi-

al incompleto;

-alta: curso colegial completo a universitário.

A classificação utilizada para escolaridade foi a proposta por Alvarenga et al, 19731, com adaptações que consistiram na junção de categorias.

- Renda:

Considerou-se a renda familiar, ou seja, todo - dinheiro disponível para a familia no mês. A renda foi convertida em salários mínimos vigentes na ocasião da entrevista. Foram consideradas as seguintes categorias:

. 0 - 4 salários mínimos;

.4 | 8 salários mínimos;

. 8 ou mais salários mínimos. 


\subsection{DIAGNÓSTICO DA ANEMIA}

- critério para diagnóstico da anemia foi o recomendado pela Organização Mundial de Saúde (OMS), que propõe, para crianças de 6 meses a 6 anos, $11 \mathrm{~g} / \mathrm{dl}$ como valor crítico de concentração de $\mathrm{Hb}$, abaixo do qual considera-se a criança anêmica9. Para menores de 6 meses, não existe um valor crítico de Hb estabelecido, dificultando o diagnóstico. Por essa razão, os resultados em relação à anemia, em crianças nessa faixa etária, foram discutidos separadamente dos demais, utilizando-se como referência a curva de concentrações médias de Ho, proposta por Brault-Dubuc, obtida com crianças sadias menores de 6 meses $^{2}$.

\subsection{ANÁLISE DOS RESULTADOS}

o estudo das variáveis, nos quatro CSEs, foi feito mediante 0 teste de associação qui-quadrado $\left(\chi^{2}\right)$, com nível de significância de 5\%. A mesma técnica foi utilizada para verificar a significância das associações entre anemia e idade, peso ao nascer, tipos de leite, freqüencia de consumo de alimentos fontes de ferro e/ou potenciadores da absorção de ferro não heme eindicadores sócio-econômicos.

A adequação da relação peso/idade foi verificada utilizando-se 0 padrão de referência do National Center of Health Statistics (NCHS) 20.

Para determinar a duração do aleitamento materno e a idade de introdução de outros leites e de alimentos não lácteos, bem como a relação dessas variáveis com a anemia, utilizou-se a técnica da tábua de vida para dados censurados ${ }^{3}$. Para comparação dos dois grupos (anêmicos e não anêmics), utilizou-se o teste qui quadrado com 1 grau de liberdade, também a 5\%. 
O tempo mediano de duração do aleitamento materno e a idade mediana de introdução de leites e outros alimentos foram obtidos a partir da tábua de vida. 


\section{RESULTADOS E DISCUSSÃO}

4.1.DESCRIÇÃO DA POPULAÇÃO

As 317 crianças que compuseram a amostra são apresentadas na tabela 1, distribuidas segundo centro de saúde e sexo.

TABELA 1 - NÚMERO E PORCENTAGEM DE CRIANÇAS, SEGUNDO CENTRO DE SAÚDE E SEXO

\begin{tabular}{|c|c|c|c|c|c|c|c|c|c|c|}
\hline \multirow{3}{*}{ SEXO } & \multicolumn{8}{|c|}{ CENTRO DE SAÚDE } & & \\
\hline & \multicolumn{2}{|c|}{1} & \multicolumn{2}{|c|}{2} & \multicolumn{2}{|c|}{3} & \multicolumn{2}{|c|}{4} & \multicolumn{2}{|c|}{ TO'TAL } \\
\hline & $\mathrm{N}$ & $\%$ & $\mathrm{~N}$ & $\%$ & $\mathrm{~N}$ & $\%$ & $\mathrm{~N}$ & $\%$ & $\mathrm{~N}$ & $\%$ \\
\hline MASC & 32 & 42,7 & 70 & 53,4 & 20 & 40,8 & 29 & 46,8 & 151 & 47,6 \\
\hline FEM & 43 & 57,3 & 61 & 46,6 & 29 & 59,2 & 33 & 53,2 & 166 & 52,4 \\
\hline TOTAL & 75 & 100 & 131 & 100 & 49 & 100 & 62 & 100 & 317 & 100 \\
\hline
\end{tabular}

As diferenças na distribuição por sexo, nos quatro CSEs, não são estatisticamente significantes.

Em relação à idade, observa-se que a maior demanda dos CSEs foi constituída por crianças menores de 6 meses (Tabela 2). E provável que isso tenha ocorrido porque o calendário de vacinas exige a presença das crianças nos serviços de saúde, com maior regularidade, nesse período. 
TABELA 2 - NÚMERO E PORCENTAGEM DE CRIANÇAS, SEGUNDO CENTRO DE SAÚdE E IDADE NO MOMENTO DA ENTREVISTA

\begin{tabular}{|c|c|c|c|c|c|c|c|c|c|c|}
\hline \multirow{3}{*}{$\begin{array}{l}\text { IDADE } \\
\text { (dias) }\end{array}$} & \multicolumn{8}{|c|}{ CENTRO DE SAÚDE } & & \\
\hline & \multicolumn{2}{|c|}{1} & \multicolumn{2}{|c|}{2} & \multicolumn{2}{|c|}{3} & \multicolumn{2}{|c|}{4} & \multicolumn{2}{|c|}{ TOTAL } \\
\hline & $\mathrm{N}$ & $\%$ & $\mathrm{~N}$ & $\%$ & $\mathrm{~N}$ & $\%$ & $\mathrm{~N}$ & $\%$ & $\mathrm{~N}$ & $\%$ \\
\hline 0_90 & 18 & 24,0 & 45 & 34,4 & 23 & 46,9 & 16 & 25,8 & 102 & 32,2 \\
\hline $91 \_180$ & 24 & 32,0 & 27 & 20,6 & 14 & 28,6 & 16 & 25,8 & 81 & 25,6 \\
\hline $181 \_270$ & 16 & 21,3 & 29 & 22,1 & 9 & 18,4 & 15 & 24,2 & 69 & 21.8 \\
\hline $271 \quad 365$ & 17 & 22.7 & 30 & 22.9 & 3 & 6,1 & 15 & 24.2 & 65 & 20,4 \\
\hline TOTAL & 75 & 100 & 131 & 100 & 49 & 100 & 62 & 100 & 317 & 100 \\
\hline
\end{tabular}

As diferenças na distribuição etária entre os CSEs não são estatisticamente significantes.

Na tabela 3, encontra-se a distribuição das crianças quanto a peso ao nascimento. Verifica-se que a maior proporção delas nasceu com peso entre $3000-3500 \mathrm{~g}(36,9 \%)$. 


\section{TABELA 3 - NÚMERO E PORCENTAGEM DE CRIANÇAS, SEGUNDO CENTRO DE SAÚDE E PESO AO NASCER}

\begin{tabular}{|c|c|c|c|c|c|c|c|c|c|c|}
\hline \multirow{3}{*}{$\begin{array}{c}\text { PESO } \\
\text { AO } \\
\text { NASCER }\end{array}$} & \multicolumn{8}{|c|}{ CENTRO DE SAÚDE } & & \\
\hline & \multicolumn{2}{|c|}{1} & \multicolumn{2}{|c|}{2} & \multicolumn{2}{|c|}{3} & \multicolumn{2}{|c|}{4} & \multicolumn{2}{|c|}{ TOTAL } \\
\hline & $\mathrm{N}$ & $\%$ & $\mathrm{~N}$ & $\%$ & $\mathrm{~N}$ & $\%$ & $\mathrm{~N}$ & $\%$ & $\mathrm{~N}$ & $\%$ \\
\hline$<2500$ & 5 & 7,0 & 12 & 9,6 & 6 & 13,1 & 8 & 13,3 & 31 & 10,2 \\
\hline $2500+3000$ & 23 & 31,9 & 36 & 28,8 & 11 & 23,9 & 13 & 21,7 & 83 & 27,4 \\
\hline $3000+3500$ & 28 & 38,9 & 47 & 37,6 & 14 & 30,4 & 23 & 38,3 & 112 & 36,9 \\
\hline $3500+4000$ & 11 & 15,3 & 23 & 18,4 & 7 & 15,2 & 14 & 23,3 & 55 & 18,2 \\
\hline $4000 e+$ & 5 & 6.9 & 7 & 5.6 & 8 & 17.4 & 2 & 3,4 & 22 & 7.3 \\
\hline \multirow[t]{2}{*}{ TOTAL* } & 72 & 100 & 125 & 100 & 46 & 100 & 60 & 100 & 303 & 100 \\
\hline & & -1 & 1,03 & & 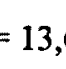 & & & & & \\
\hline
\end{tabular}

A proporção de crianças com baixo peso ao nascer $(<2500 \mathrm{~g})$ foi $10,2 \frac{0}{2}$. Este valor é superior àquele encontrado no município de Sào Paulo (8,7\%), em 1984-8531, e àquele verificado para toda a região sul do Brasil $(7,8 \%)^{35}$. E superior, também, aos valores observados em dois estudos realizados no município de são Paulo, em maternidades ${ }^{32}$ e em um centro de saúde ${ }^{55}$, que mostraram, respectivamente, $9,7 \%$ e $6,5 \%$ de crianças com baixo peso ao nascer.

Chama a atenção a proporção de crianças com peso superior a $4000 \mathrm{~g}(17,4 \%)$ verificada no CSE3. A maior proporção de crianças com peso baixo e inadequado foi verificada no $\operatorname{CSE} 1(38,9)$, seguido pelo CSE2 $(38,4)$.

As diferenças de peso encontradas entre as crianças dos quatro CSEs não são estatisticamente significantes.

A distribuição das crianças segundo idade do pai e da mãe é apresentada nas tabelas 4 e 5, respectivamente. 
TABELA 4 - NÚMERO E PORCENTAGEM DE CRIANÇAS, SEGUNDO CENTRO DE SAÚDE E IDADE DO PAI

\begin{tabular}{|c|c|c|c|c|c|c|c|c|c|c|}
\hline \multirow{3}{*}{$\begin{array}{l}\text { IDADE } \\
\text { DO PAI } \\
\text { (em anos) }\end{array}$} & \multicolumn{8}{|c|}{ CENTRO DE SAÚDE } & & \\
\hline & \multicolumn{2}{|c|}{1} & \multicolumn{2}{|c|}{2} & \multicolumn{2}{|c|}{3} & \multicolumn{2}{|c|}{4} & \multicolumn{2}{|c|}{ TOTAL } \\
\hline & $N$ & $\%$ & $\mathrm{~N}$ & $\%$ & $\mathrm{~N}$ & $\%$ & $\mathrm{~N}$ & $\%$ & $\mathrm{~N}$ & $\%$ \\
\hline$<20$ & 2 & 2,9 & 3 & 2,4 & 6 & 13,0 & 1 & 1,7 & 12 & 4,0 \\
\hline $20 \vdash 30$ & 26 & 37,7 & 68 & 54,8 & 16 & 34,8 & 32 & 53,3 & 142 & 47,5 \\
\hline $30 \mathrm{e}+$ & 41 & 59,4 & 53 & 42,8 & 24 & 52.2 & 27 & 45.0 & 145 & 48.5 \\
\hline TOTAL* & 69 & 100 & 124 & 100 & 46 & 100 & 60 & 100 & 299 & 100 \\
\hline
\end{tabular}

*não incluídas 18 crianças por falta de informação.

Verifica-se que a proporção de pais com menos de 20 anos, encontrada no CSE3, foi bem maior que nos demais serviços. Os CSEs 2 e 4 tinham mais da metade dos pais com idades entre 20 e 30 anos, enquanto que os CSEs 1 e 3 tinham essa mesma proporção de pais com 30 ou mais anos. Entretanto, as diferenças verificadas, comparando-se os quatro serviços, são estatisticamente significantes.

Na tabela 5, verifica-se que a maior proporção das mães, nos CSEs, tinham idades entre 20 e 30 anos, faixa considerada a mais adequada à gestação. 
TABELA 5 - NÚMERO E PORCENTAGEM DE CRIANÇAS, SEGUNDO CENTRO DE SAÚdE E IDADE DA MĀE

\begin{tabular}{|c|c|c|c|c|c|c|c|c|c|c|}
\hline \multirow{3}{*}{$\begin{array}{c}\text { IDADE } \\
\text { DA MÃE } \\
\text { (em anos) }\end{array}$} & \multicolumn{8}{|c|}{ CENTRO DE SAÚDE } & & \\
\hline & \multicolumn{2}{|c|}{1} & \multicolumn{2}{|c|}{2} & \multicolumn{2}{|c|}{3} & \multicolumn{2}{|c|}{4} & \multicolumn{2}{|c|}{ TOTAL } \\
\hline & $\mathrm{N}$ & $\%$ & $\mathrm{~N}$ & $\%$ & $\mathrm{~N}$ & $\%$ & $\mathrm{~N}$ & $\%$ & $\mathrm{~N}$ & $\%$ \\
\hline$<20$ & 8 & 10,7 & 16 & 12,4 & 9 & 18,4 & 8 & 12,9 & 41 & 13,0 \\
\hline $20+30$ & 41 & 54,7 & 84 & 65,1 & 24 & 49,0 & 33 & 53,2 & 182 & 57,8 \\
\hline $30 \mathrm{e}+$ & 26 & 34.6 & 29 & 22,5 & 16 & 32.6 & 21 & 33.9 & 92 & 29.2 \\
\hline \multirow[t]{2}{*}{ TOTAL* } & 75 & 100 & 129 & 100 & 49 & 100 & 62 & 100 & 315 & 100 \\
\hline & & $5 \mathrm{gl})=$ & & & 7,07 & & & & & \\
\hline
\end{tabular}

Nota-se, também, que as proporções de mães adolescentes (com menos de 20 anos) foram maiores que as verificadas para os pais (tabela 4). O CSE3 foi aquele que apresentou a maior proporção de mães nessas condições $(18,4 \%)$.

As diferenças verificadas na distribuição de idades das mães, entre os CSEs, não são estatisticamente significantes.

Os resultados em relação à escolaridade do pai são apresentados na tabela 6 


\section{TABELA 6 - NÚMERO E PORCENTAGEM DE CRIANÇAS, SEGUNDO CENTRO DE SAÚDE E ESCOLARIDADE DO PAI}

\begin{tabular}{|c|c|c|c|c|c|c|c|c|c|c|}
\hline \multirow{3}{*}{$\begin{array}{c}\text { ESCOLARI- } \\
\text { DADE DO } \\
\text { PAI }\end{array}$} & \multicolumn{8}{|c|}{ CENTRO DE SAÚDE } & & \\
\hline & \multicolumn{2}{|c|}{1} & \multicolumn{2}{|c|}{2} & \multicolumn{2}{|c|}{3} & \multicolumn{2}{|c|}{4} & \multicolumn{2}{|c|}{ TOTAL } \\
\hline & $\mathrm{N}$ & $\%$ & $\mathrm{~N}$ & $\%$ & $\mathrm{~N}$ & $\%$ & $\mathrm{~N}$ & $\%$ & $\mathrm{~N}$ & $\%$ \\
\hline NENHUMA & 4 & 6,5 & 6 & 5,5 & 2 & 4,8 & 9 & 16,7 & 21 & 7,9 \\
\hline BAIXA & 10 & 16,1 & 15 & 13,8 & 8 & 19,0 & 10 & 18,5 & 43 & 16,1 \\
\hline MÉDIA BALXA & 19 & 30,6 & 53 & 48,6 & 17 & 40,5 & 13 & 24,0 & 102 & 38,2 \\
\hline MÉDIA ALTA & 15 & 24,2 & 23 & 21,1 & 9 & 21,4 & 11 & 20,4 & 58 & 21,7 \\
\hline ALTA & 14 & 22.6 & 12 & 11.0 & 6 & 14,3 & 11 & 20.4 & 43 & 16.1 \\
\hline \multirow[t]{2}{*}{ TOTAL* } & 62 & 100 & 109 & 100 & 42 & 100 & 54 & 100 & 267 & 100 \\
\hline & & & & & & & 09 & & & \\
\hline
\end{tabular}

*não incluídas 50 crianças por falta de informação.

Nota-se que mais da metade dos pais tinham, no máximo, escolaridade média baixa (primário completo a ginasial incompleto). o CSE4 foi aquele que teve a maior proporção de pais sem qualquer escolaridade. Entretanto, esse mesmo serviço e o CSE1 foram aqueles que apresentaram as maiores proporções de pais com alta escolaridade (colegial completo a universitário).

Verificou-se que $16 \%$ das mães não souberam informar $\circ$ nivel de escolaridade dos pais. A proporção com que ocorreu a ausência de informação foi muito semelhante nos 4 serviços.

As diferenças encontradas entre os CSEs não são estatisticamente significantes.

A escolaridade da mãe é apresentada na tabela 7. 
TABELA 7 - NÚMERO E PORCENTAGEM DE CRIANÇAS, SEGUNDO CENTRO DE SAÚDE E ESCOLARIDADE DA MÃE

\begin{tabular}{|c|c|c|c|c|c|c|c|c|c|c|}
\hline \multirow{3}{*}{$\begin{array}{c}\text { ESCOLARI- } \\
\text { DADE DA } \\
\text { MÃE }\end{array}$} & \multicolumn{8}{|c|}{ CENTRO DE SAÚDE } & & \\
\hline & \multicolumn{2}{|c|}{1} & \multicolumn{2}{|c|}{2} & \multicolumn{2}{|c|}{3} & \multicolumn{2}{|c|}{4} & \multicolumn{2}{|c|}{ TOTAL } \\
\hline & $\mathrm{N}$ & $\%$ & $N$ & $\%$ & $\mathrm{~N}$ & $\%$ & $N$ & $\%$ & $\mathrm{~N}$ & $\%$ \\
\hline NENHUMA & 2 & 2,7 & 2 & 1,6 & 1 & 2,1 & 10 & 16,7 & 15 & 4,8 \\
\hline BAIXA & 14 & 18,7 & 25 & 19,4 & 9 & 18,8 & 14 & 23,3 & 62 & 19,9 \\
\hline MÉD. BAIXA & 28 & 37,3 & 62 & 48,1 & 22 & 45,8 & 23 & 38,3 & 135 & 43,3 \\
\hline MÉDIA ALTA & 12 & 16,0 & 29 & 22,5 & 9 & 18,7 & 8 & 13,3 & 58 & 18.6 \\
\hline ALTA & 19 & 25,3 & 11 & 8.5 & 7 & 14.6 & 5 & 8.3 & 42 & 13.5 \\
\hline \multirow[t]{2}{*}{ TOTAL* } & 75 & 100 & 129 & 100 & 48 & 100 & 60 & 100 & 312 & 100 \\
\hline & & 2gl) & 03 & & & &, 00 & & & \\
\hline
\end{tabular}

Chama a atenção 0 fato de que $40 \%$ das mães do CSE 4 se encontravam nas categorias de nenhuma e baixa escolaridades (curso primário incompleto), proporção essa que é o dobro da verificada nos demais centros de saúde. No CSE1, havia 25,3믕 das mães com alta escolaridade (curso colegial completo a universitário), proporção muito maior que a encontrada nos demais serviços.

Essas diferenças de escolaridade das mães, nos CSEs, são estatisticamente significantes.

Comparando-se as escolaridades do pai e da mãe (tabelas 6 e 7), nota-se que as distribuições são semelhantes. Entretanto, no CSE4, chama a atenção a grande diferença verificada para escolaridade alta - 20,4\% para pais e 8,3\% para mães -

A categoria de escolaridade que concentra a maior proporção de mães e pais é a média baixa que representa, no mínimo, 4 
anos de freqüência à escola. Em 1992, as Nações Unidas apresentaram dados do Programa de Desenvolvimento Humano que mostram, para - Brasil como um todo, a média de 3,9 anos de escolaridade para adultos de ambos os sexos. O mesmo estudo mostra, também para adultos, média de alfabetização de $81,1 \% 70$. No presente estudo a proporcão de indvíduos com escolaridade é de 92,1\% para homens e 95,20 para mulheres.

Em relação à renda, verifica-se, na tabela 8, que quase metade das crianças estudadas faziam parte de familias com renda mensal até 4 salários mínimos.

TABELA 8 - NÜMERO E PORCENTAGEM DE CRIANÇAS, SEGUNDO CENTRO DE SAÚDE E RENDA FAMILIAR EM SALÁRIOS MÍNIMOS

\begin{tabular}{|c|c|c|c|c|c|c|c|c|c|c|}
\hline \multirow{3}{*}{$\begin{array}{c}\text { RENDA } \\
\text { FAMILIAR } \\
\text { (SAL.MIN.) }\end{array}$} & \multicolumn{8}{|c|}{ CENTRO DE SAÚDE } & & \\
\hline & \multicolumn{2}{|c|}{1} & \multicolumn{2}{|c|}{2} & \multicolumn{2}{|c|}{3} & \multicolumn{2}{|c|}{4} & \multicolumn{2}{|c|}{ TOTAL } \\
\hline & $\mathrm{N}$ & $\%$ & $\mathrm{~N}$ & $\%$ & $\mathrm{~N}$ & $\%$ & $\mathrm{~N}$ & $\%$ & $\mathrm{~N}$ & $\%$ \\
\hline $0 \vdash 4$ & 20 & 36,4 & 44 & 44,5 & 13 & 34,2 & 35 & 66,0 & 112 & 45,7 \\
\hline $4 \vdash 8$ & 20 & 36,4 & 37 & 37,3 & 16 & 42,1 & 9 & 17,0 & 82 & 33,5 \\
\hline $8 \mathrm{e}+$ & 15 & 27,2 & 18 & 18,2 & 9 & 23,7 & 9 & 17,0 & 51 & 20.8 \\
\hline TOTAL* & 55 & 100 & 99 & 100 & 38 & 100 & 53 & 100 & 245 & 100 \\
\hline & & 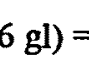 & & & 14, & &, 02 & & & \\
\hline
\end{tabular}

A população do CSE4 foi a que apresentou piores condições de renda, concentrando $66 \%$ da população estudada nas faixas inferiores a 4 salários mínimos. Os demais CSES apresentaram melhores condições, concentrando mais da metade da população nas faixas de renda superiores a 4 salários mínimos. 
No periodo de 1984-85, foi verificado, no CS1, que 75,3응 das familias estudadas tinham renda de até 4 salários mínimos 55 , evidenciando melhores condições da população, no presente estudo, em relação a essa variável. Esse fato permite a hipótese de que, pelo menos nesse serviço, tenha aumentado a demanda de população com melhores niveis de renda que anteriormente não freqüentava esse tipo de serviço.

Da mesma forma que ocorreu com a escolaridade das mães, as diferenças de renda, verificadas entre as populações dos CSEs, são estatisticamente significantes.

Quanto à concentração de $\mathrm{Hb}$ das crianças, verifica-se, na tabela 9, que 14,58 delas apresentaram valores inferiores a $11 \mathrm{~g} / \mathrm{dl}$, sendo esta, portanto, a prevalência da anemia na população estudada, que é mais baixa que as verificadas em outras pesquisas $31,45,71$.

\section{TABELA 9 - NÜMERO E PORCENTAGEM DE CRIANÇAS SEGUNDO CENTRO DE SAÚDE E CONCENTRAÇĀO DE HEMOGLOBINA}

\begin{tabular}{|c|c|c|c|c|c|c|c|c|c|c|}
\hline \multirow{3}{*}{$\begin{array}{c}\mathrm{Hb} \\
(\mathrm{g} / \mathrm{dl})\end{array}$} & \multicolumn{8}{|c|}{ CENTRO DE SAÚDE } & & \\
\hline & \multicolumn{2}{|c|}{1} & \multicolumn{2}{|c|}{2} & \multicolumn{2}{|c|}{3} & \multicolumn{2}{|c|}{4} & \multicolumn{2}{|c|}{ TOTAL } \\
\hline & $\mathbf{N}$ & $\%$ & $\mathbf{N}$ & $\%$ & $\mathbf{N}$ & $\%$ & $\mathbf{N}$ & $\%$ & $\mathrm{~N}$ & $\%$ \\
\hline$<11,0$ & 12 & 16,0 & 20 & 15,3 & 2 & 4,1 & 12 & 19,4 & 46 & 14,5 \\
\hline$>11.0$ & 63 & 84.0 & 111 & 84,7 & 47 & 95.9 & 50 & 80.6 & 271 & 85.5 \\
\hline TOTAL & 75 & 100 & 131 & 100 & 49 & 100 & 62 & 100 & 317 & 100 \\
\hline
\end{tabular}

Em levantamento feito em $80 \%$ dos prontuários das crianças maiores de 3 meses, nos quatro CSEs, verificou-se a prescrição de sulfato ferroso para $5,4 \%$ das crianças da amostra. Conside- 
rando-se que, para a formação da amostra, haviam sido excluídas as crianças que estavam tomando medicamentos, esperava-se essa baixa proporção de indicação de sulfato ferroso, o que, no entanto, não deve ter interferido na prevalência da anemia.

O CSE4 foi o que apresentou a maior proporção de crianças com Hb inferior a $11 \mathrm{~g} / \mathrm{dl}\left(19,4 \frac{\circ}{\circ}\right)$ e o centro com a menor proporção foi o CSE3 $\left(4,1 \frac{0}{0}\right)$. A prevalência muito baixa verificada nesse serviço pode ter sido devida à grande proporção de crianças com menos de 6 meses $-75,50$ - na amostra estudada. Dessa proporção 46,9\% eram menores de 3 meses. Sabe-se que os níveis de Hb no início da vida, em crianças normais, são elevados ${ }^{2}$ e que, portanto, a prevalência da anemia, considerando-se $11 \mathrm{~g} / \mathrm{dl}$ de $\mathrm{Hb}$ como valor critico, provavelmente seja baixa.

As diferenças nos niveis de $\mathrm{Hb}$ verificadas nos quatro serviços não são estatisticamente significantes.

Os resultados obtidos a partir da análise das variáveis estudadas para caracterizar a população mostram que existem semelhanças e algumas diferenças entre os CSEs. Embora verifiquem-se diferenças estatisticamente significantes entre os quatro CSEs, em relação à idade do pai, escolaridade da mãe e renda familiar, nota-se que não existe um padrão, nessas desigualdades, que possa tornar um dos serviços de saúde absolutamente diferente dos demais. Destacando-se, ainda, que os serviços não se distinguem estatisticamente quanto às concentrações de $\mathrm{Hb}$ de sua clientela, optou-se por trabalhar com a população como um todo, sem distribuíla por centro de saúde. 
4.2.DESCRIÇÃO DA PRATICA ALIMENTAR

- tipo de alimentação que estava sendo consumido pelas crianças, na ocasião da entrevista, é apresentado na tabela 10.

TABELA 10 - NÚMERO E PORCENTAGEM DE CRIANÇAS, SEGUNDO IDADE E TIPO DE ALIMENTAÇÃO

\begin{tabular}{|c|c|c|c|c|c|c|c|c|c|c|}
\hline \multirow{3}{*}{$\begin{array}{l}\text { TIPO DE } \\
\text { ALIMEN- } \\
\text { TACCÃO* }\end{array}$} & \multicolumn{8}{|c|}{ IDADE (dias) } & & \\
\hline & \multicolumn{2}{|c|}{$0-90$} & \multicolumn{2}{|c|}{$91-180$} & \multicolumn{2}{|c|}{$181-270$} & \multicolumn{2}{|c|}{$271-365$} & \multicolumn{2}{|c|}{ TOTAL } \\
\hline & $\mathrm{N}$ & $\%$ & $\mathrm{~N}$ & $\%$ & $\mathrm{~N}$ & $\%$ & $\mathrm{~N}$ & $\%$ & $\mathrm{~N}$ & $\%$ \\
\hline A.M.E. & 43 & 42,2 & 12 & 14,8 & 3 & 4,3 & 0 & - & 58 & 18.3 \\
\hline A.A.E. & 19 & 18,6 & 6 & 7,4 & 0 & - & 0 & - & 25 & 7,9 \\
\hline A.M. & 33 & 32,4 & 6 & 7,4 & 2 & 2,9 & 1 & 1,5 & 42 & 13,2 \\
\hline M.N.L. & 1 & 1,0 & 8 & 9,9 & 9 & 13,0 & 4 & 6,2 & 22 & 6,9 \\
\hline A.N.L. & 2 & 2,0 & 39 & 48,1 & 46 & 66,7 & 47 & 72,3 & 134 & 42,3 \\
\hline M.A.N.L. & 4 & 3.9 & 10 & 12,3 & 9 & 13.0 & 13 & 20,0 & 36 & 11.4 \\
\hline \multirow[t]{7}{*}{ TOTAL } & 102 & 100 & 81 & 100 & 69 & 100 & 65 & 100 & 317 & 100 \\
\hline & ${ }^{*} \mathrm{AME}$ & \multicolumn{7}{|c|}{ - aleitamento materno exclusivo } & & \\
\hline & $\mathrm{AAE}$ & \multicolumn{7}{|c|}{ - aleitamento artificial exclusivo } & & \\
\hline & AM & \multicolumn{7}{|c|}{ - aleitamento misto } & & \\
\hline & MNL & \multicolumn{7}{|c|}{ - aleitamento materno + alimentos não lácteos } & & \\
\hline & ANL & \multicolumn{7}{|c|}{ - aleitamento artificial + alimentos não lácteos } & & \\
\hline & MANL & \multicolumn{7}{|c|}{ - aleitamento misto + alimentos não lácteos } & & \\
\hline
\end{tabular}

Nota-se que, entre as crianças com idades até 90 dias, 42,2\% estavam em aleitamento materno exclusivo, e 51\% já estavam em aleitamento misto ou artificial, enquanto 6,9 우 já consumiam alimentos não lácteos. 
Considerando-se como situação ideal o aleitamento materno exclusivivo até 6 meses46, verifica-se que o desmame ocorreu precocemente, apesar de se tratar de população que frequienta centro de saúde escola, onde o incentivo a essa prática é constante. Apenas 14,8\% das crianças com idades entre 3 e 6 meses estavam em aleitamento materno exclusivo. Apesar do desmame ter se iniciado precocemente, $27,7 \%$ das crianças com idades acima de 9 meses ainda recebiam leite materno.

$\mathrm{Na}$ população total, $49,8 \%$ das crianças recebiam leite materno, até o momento da entrevista, de forma exclusiva ou não. Esse fato demonstra que embora a duração do aleitamento materno exclusivo seja pequena, o mesmo não acontece em relação ao aleitamento materno total que, para boa parte das crianças, estende-se até o final do primeiro ano de vida.

Entre as crianças que estavam em aleitamento artificial, exclusivo ou não, verificou-se o tipo de leite utilizado quando da sua introdução na alimentação. Os resultados são apresentados na tabela 11 .

TABELA 11 - TIPOS DE LEITE QUANDO INICIADA SUA UTILIZAÇÃO

\begin{tabular}{ccc}
\hline & \multicolumn{2}{c}{ CRIANÇAS } \\
\cline { 2 - 3 } TIPO DE LEITE & $\mathrm{N}$ & $\%$ \\
\hline FLUÚDO & 35 & 15,3 \\
INTEGRAL (em pó) & 86 & 37,5 \\
FORMULADO & 108 & 47.2 \\
\hline TOTAL & 229 & 100 \\
\hline
\end{tabular}

*não incluidas 8 crianças por falta de informação

Nesses resultados, chamam a atenção a pequena proporção de crianças que receberam leite fluido e o fato de que quase metade da população tenha recebido leite formulado. Na população 
infantil do município de São Paulo, encontrou-se a mesma caracteristica em relação ao leite fluido, porém a proporção de crianças que utilizavam leite modificado era insignificante ${ }^{54,64}$.

Sabe-se que, quando se inicia o aleitamento artificial, sobretudo antes dos seis meses de vida, o leite formulado é o mais indicado e que, por ser enriquecido com ferro, deve proteger a criança da anemia. A prática verificada talvez esteja refletindo a orientação que é feita nesse sentido.

Ainda em relação às crianças que estavam em aleitamento artificial ou misto, verifica-se que a idade média de introdução de leites foi 1,7 meses. Para essas crianças, observou-se o número de mamadeiras de leite ingeridas por dia, o que pode ser visto na tabela 12 .

\section{TABELA 12 - NÚMERO E PORCENTAGEM DE CRIANÇAS EM ALEITAMENTO ARTIFICIAL, SEGUNDO IDADE E NÚMERO DE MAMADEIRAS DE LEITE POR DIA}

\begin{tabular}{cccccccccccc}
\hline & \multicolumn{10}{c}{ IDADE (dias) } & \multicolumn{1}{c}{ TOTAL } \\
\cline { 2 - 10 } NÚMERO DE & \multicolumn{2}{c}{$0-90$} & \multicolumn{1}{c}{$91-180$} & \multicolumn{2}{c}{$181-270$} & \multicolumn{2}{c}{$271-365$} & \multicolumn{2}{c}{ TOTA } \\
MAMAD. & $\mathrm{N}$ & $\%$ & $\mathrm{~N}$ & $\%$ & $\mathrm{~N}$ & $\%$ & $\mathrm{~N}$ & $\%$ & $\mathrm{~N}$ & $\%$ \\
\hline 1 a 3 & 24 & 42,1 & 24 & 40,0 & 34 & 60,7 & 42 & 70,0 & 125 & 53,4 \\
4 a 6 & 26 & 45,6 & 33 & 55,0 & 21 & 37,5 & 18 & 30,0 & 98 & 41,9 \\
7 e mais & 7 & 12,3 & 3 & 5,0 & 1 & 1,8 & 0 & 0,0 & 11 & 4,7 \\
\hline TOTAL* & 57 & 100 & 60 & 100 & 57 & 100 & 60 & 100 & 234 & 100 \\
\hline
\end{tabular}

* não incluidas 3 crianças por falta de informação.

Nota-se que o número de mamadeiras diárias diminuiu com - aumento da idade. Isso ocorreu porque, no início da vida,a alimentação é exclusivamente láctea $e$, à medida que vão sendo introduzidos outros alimentos, estes vão substituindo o leite. 
Em função dessa observação, chama a atenção a grande proporção de crianças com mais de 6 meses $(37,5 \%$ e $30 \%$ ) que recebiam 4 a 6 mamadeiras por dia, sugerindo que a substituição do leite pela refeição de sal ainda era incompleta ou inexistente. outra hipótese é a de que o leite estava sendo usado na complementação das refeições. Esta última sugestão é corroborada pelos dados apresentados na tabela 13.

TABELA 13 - NÚMERO E PORCENTAGEM DE CRIANÇAS QUE RECEBIAM ALIMENTOS NÃO LÁCTEOS, SEGUNDO IDADE E NÚMERO DE REFEIÇÕES POR DIA

\begin{tabular}{cccccccccccc}
\hline & \multicolumn{10}{c}{ IDADE (dias) } & \multicolumn{1}{c}{} \\
\cline { 2 - 10 } NÚMERO DE & \multicolumn{2}{c}{$0-90$} & \multicolumn{1}{c}{$91-180$} & \multicolumn{1}{c}{$181-270$} & $271-365$ & \multicolumn{2}{c}{ TOTAL } \\
REFEIÇÕES & $\mathrm{N}$ & $\%$ & $\mathrm{~N}$ & $\%$ & $\mathrm{~N}$ & $\%$ & $\mathrm{~N}$ & $\%$ & $\mathrm{~N}$ & $\%$ \\
\hline 1 & 6 & 85,7 & 42 & 73,7 & 11 & 17,2 & 7 & 11,1 & 66 & 34,6 \\
2 & 1 & 14,3 & 12 & 22,8 & 47 & 73,4 & 49 & 77,8 & 110 & 57,6 \\
$3-5$ & 0 & 0,0 & 2 & 3,5 & 6 & 9,5 & 7 & 11,1 & 15 & 7,8 \\
\hline TOTAL* & 7 & 100 & 57 & 100 & 64 & 100 & 63 & 100 & 191 & 100 \\
\hline
\end{tabular}

* nào incluída 1 criança por falta de informação.

Verifica-se que entre as crianças mais velhaslacima de 6 meses), a maior parte fazia duas refeições diárias, como esperado. Entre aquelas que recebiam precocemente alimentos não lácteos (menores de 6 meses), nota-se que a maior proporção fazia apenas uma refeição diária. As crianças que faziam três a cinco refeições eram aquelas que recebiam alimentos não lácteos, acompanhados ou não de leite, nos intervalos entre as refeições principais. Cabe ressaltar que, nesse caso, consideraram-se, além dos alimentos destacados pelo papel na etiologia da anemia, outros como: pão, iogurte, doce, bolacha, etc. 
Foram verificadas as idades em que foram introduzidos os alimentos destacados por serem fontes de ferro e/ou potenciadores da absorção do ferro não heme. Os resultados são apresentados na tabela 14.

\begin{tabular}{|c|c|c|c|c|c|c|c|c|c|c|}
\hline \multirow{3}{*}{$\begin{array}{c}\text { IDADE } \\
\text { (em dias) }\end{array}$} & \multicolumn{10}{|c|}{ ALIMENTOS INTRODUZIDOS } \\
\hline & \multicolumn{2}{|c|}{ FRUTA } & \multicolumn{2}{|c|}{ CARNE } & \multicolumn{2}{|c|}{ FEIJÃO } & \multicolumn{2}{|c|}{ GEMA } & \multicolumn{2}{|c|}{ HORTAL. } \\
\hline & $\mathrm{N}$ & $\%$ & $\mathrm{~N}$ & $\%$ & $\mathrm{~N}$ & $\%$ & $\mathrm{~N}$ & $\%$ & $\mathrm{~N}$ & $\%$ \\
\hline $0-90$ & 107 & 57,5 & 29 & 20,9 & 7 & 9,3 & $\overline{16}$ & 12,8 & 26 & $\overline{24,3}$ \\
\hline $91-180$ & 77 & 41,4 & 94 & 67,6 & 45 & 60,0 & 88 & 70,4 & 70 & 65,4 \\
\hline $181-270$ & 2 & 1,1 & 16 & 11,5 & 19 & 25,3 & 19 & 15,2 & 9 & 8,4 \\
\hline $271-365$ & 0 & - & 0 & - & 4 & 5,3 & 2 & 1,6 & 2 & 1.9 \\
\hline TOTAL & 186 & 100 & 139 & 100 & 75 & 100 & 125 & 100 & 107 & 100 \\
\hline $\begin{array}{l}\text { IDADE } \\
\text { MÉDIA }\end{array}$ & \multicolumn{2}{|c|}{3,4} & \multicolumn{2}{|c|}{4,6} & \multicolumn{2}{|c|}{5,8} & \multicolumn{2}{|c|}{5,2} & \multicolumn{2}{|c|}{4,7} \\
\hline $\begin{array}{c}\text { NÃO } \\
\text { INQÚDAS* }\end{array}$ & \multicolumn{2}{|c|}{4} & \multicolumn{2}{|c|}{3} & \multicolumn{2}{|c|}{1} & \multicolumn{2}{|c|}{5} & \multicolumn{2}{|c|}{3} \\
\hline
\end{tabular}

*por falta de informação

Entre as 192 crianças que, até o momento da entrevista, já recebiam alimentos não lácteos (tabela 10), 190 (98,9\%), ou seja, praticamente a totalidade delas, já haviam introduzido frutas. Dessas, 57,5\% começaram a receber esse alimento no primeiro trimestre de vida.

Em relação à carne, 72,4\% das crianças já a consumiam; - feijão fazia parte da alimentação de apenas 39,1\% das 192 crianças, mostrando, conforme verificado em outra pesquisa64, que seu consumo é baixo no primeiro ano de vida, aumentando a partir do segundo ano.

Em relação à gema e hortaliças, a introdução ocorreu, respectivamente, para $65,1 \%$ e 55,7응 das crianças. Nota-se que, com 
exceção das frutas, a maior proporção das introduções de alimentos ocorreu entre 3 e 6 meses de idade.

Tomando-se como referência a orientação com relação à prática alimentar no primeiro ano de vida, que recomenda a ingestão exclusiva do leite materno até os 6 meses 28,46 , observa-se que as idades médias de introdução dos alimentos foram muito baixas. Entretanto, se a criança estiver em aleitamento misto ou artificial, a recomendação é a de que se inicie a introdução de alimentos não lácteos entre 4 e 6 meses de vida 46 . Considerando-se que, na população em questão, 51\% das crianças com até 3 meses de idade (tabela 10) se encontravam nessa situação, talvez explique-se a introdução desses alimentos nessa faixa etária, que passa a ser adequada, pois a criança não se encontrava em aleitamento materno exclusivo.

A freqüência semanal de consumo dos alimentos não lácteos, relativa ao último mês, bem como o consumo dos mesmos, no dia anterior, estão descritos nas tabelas 15 a 24 .

TABELA 15 - NÚMERO E PORCENTAGEM DE CRIANÇAS QUE JÁ HAVIAM INTRODUZIDO FRUTAS NA ALIMENTAÇÃO, SEGUNDO IDADE E FREQÜÊNCIA SEMANAL DE CONSUMO NO ÚLTIMO MÊS

\begin{tabular}{cccccccccccc}
\hline CONSUMO & \multicolumn{10}{c}{ IDADE (dias) } \\
\cline { 2 - 9 } DE FRUTAS & \multicolumn{2}{c}{$0-90$} & \multicolumn{1}{c}{$91-180$} & \multicolumn{1}{c}{$181-270$} & \multicolumn{2}{c}{$271-365$} & \multicolumn{2}{c}{ TOTAL } \\
(semanal) & $\mathrm{N}$ & $\%$ & $\mathrm{~N}$ & $\%$ & $\mathrm{~N}$ & $\%$ & $\mathrm{~N}$ & $\%$ & $\mathrm{~N}$ & $\%$ \\
\hline DIARIA/ & 4 & 66,7 & 43 & 76,8 & 41 & 64,1 & 50 & 79,4 & 138 & 73,0 \\
2a6 VEZES & 2 & 33,3 & 13 & 23,2 & 21 & 32,9 & 10 & 15,9 & 46 & 24,3 \\
1 VEZ ou - & 0 & - & 0 & - & 2 & 3,1 & 1 & 1,6 & 3 & 1,6 \\
NÃO CONS. & 0 & - & 0 & - & 0 & - & 2 & 3,1 & 2 & 1.1 \\
\hline TOTAL & 6 & 100 & 56 & 100 & 64 & 100 & 63 & 100 & 189 & 100 \\
\hline
\end{tabular}

*não incluída 1 criança por falta de informação. 
TABELA 16 - NÚMERO E PORCENTAGEM DE CRIANÇAS QUE JÁ HAVIAM INTRODUZIDO FRUTAS NA DIETA, SEGUNDO IDADE E CONSUMO NO DIA ANTERIOR

\begin{tabular}{ccccccccccc}
\hline & \multicolumn{10}{c}{ IDADE (dias) } \\
\cline { 2 - 10 } CONSUMO & \multicolumn{1}{c}{$0-90$} & \multicolumn{1}{c}{$91-180$} & $181-270$ & $271-365$ & \multicolumn{2}{c}{ TOTAL } \\
DE FRUTAS & $\mathrm{N}$ & $\%$ & $\mathrm{~N}$ & $\%$ & $\mathrm{~N}$ & $\%$ & $\mathrm{~N}$ & $\%$ & $\mathrm{~N}$ & $\%$ \\
\hline SIM & 4 & 66,7 & 46 & 82,1 & 48 & 75,0 & 48 & 80,0 & 146 & 78,5 \\
NÃO & 2 & 33.3 & 10 & 17.9 & 16 & 25.0 & 12 & 20.0 & 40 & 21.5 \\
\hline TOTAL* & 6 & 100 & 56 & 100 & 64 & 100 & 60 & 100 & 186 & 100 \\
\hline
\end{tabular}

* não incluidas 4 crianças por falta de informação

TABELA 17 - NÚMERO E PORCENTAGEM DE CRIANÇAS QUE JÁ HAVIAM INTRODUZIDO CARNE NA DIETA, SEGUNDO IDADE E FREQÜÊNCIA SEMANAL DE CONSUMO NO ÚLTIMO MÊS

\begin{tabular}{|c|c|c|c|c|c|c|c|c|c|c|}
\hline \multirow{3}{*}{$\begin{array}{l}\text { CONSUMO } \\
\text { DE CARNE }\end{array}$} & \multicolumn{8}{|c|}{ IDADE (dias) } & & \\
\hline & \multicolumn{2}{|c|}{$0-90$} & \multicolumn{2}{|c|}{$91-180$} & \multicolumn{2}{|c|}{$181-270$} & \multicolumn{2}{|c|}{$271-365$} & \multicolumn{2}{|c|}{ TOTAL } \\
\hline & $\mathrm{N}$ & $\%$ & $\mathrm{~N}$ & $\%$ & $\mathrm{~N}$ & $\%$ & $\mathrm{~N}$ & $\%$ & $\mathrm{~N}$ & $\%$ \\
\hline DIÁRIO & 1 & 100 & 19 & 76,0 & 35 & 63,6 & 39 & 67,2 & 94 & 67,6 \\
\hline 2 a 6 VEZES & 0 & - & 4 & 16,0 & 15 & 27,3 & 12 & 20,7 & 31 & 22,3 \\
\hline $1 \mathrm{VEZ} \mathrm{OU} \mathrm{-}$ & 0 & - & 2 & 8,0 & 5 & 9,1 & 5 & 8,6 & 12 & 8,7 \\
\hline NÃO CONS. & 0 & - & 0 & - & 0 & - & 2 & 3,3 & 2 & 1.4 \\
\hline TOTAL* & 1 & 100 & 25 & 100 & 55 & 100 & 58 & 100 & 139 & 100 \\
\hline
\end{tabular}

*não incluidas 3 crianças por falta de informação 
TABELA 18 - NÚMERO E PORCENTAGEM DE CRIANÇAS QUE JÁ HAVIAM INTRODUZIDO CARNE NA DIETA, SEGUNDO CONSUMO NO DIA ANTERIOR

\begin{tabular}{|c|c|c|c|c|c|c|c|c|c|c|}
\hline \multirow{3}{*}{$\begin{array}{l}\text { CONSUMO } \\
\text { DE CARNE }\end{array}$} & \multicolumn{8}{|c|}{ IDADE (dias) } & & \\
\hline & \multicolumn{2}{|c|}{$0-90$} & \multicolumn{2}{|c|}{$91-180$} & \multicolumn{2}{|c|}{$181-270$} & \multicolumn{2}{|c|}{$271-365$} & \multicolumn{2}{|c|}{ TOTAL } \\
\hline & $\mathrm{N}$ & $\%$ & $\mathrm{~N}$ & $\%$ & $\mathrm{~N}$ & $\%$ & $\mathrm{~N}$ & $\%$ & $\mathrm{~N}$ & $\%$ \\
\hline SIM & 1 & 100 & 19 & 73,0 & 35 & 63,6 & 39 & 68.4 & 94 & 67,6 \\
\hline NÃO & 0 & $=$ & 7 & 27.0 & 20 & 36.4 & 18 & 31.6 & 45 & 32.4 \\
\hline TOTAL* & 1 & 100 & 26 & 100 & 55 & 100 & 57 & 100 & 139 & 100 \\
\hline
\end{tabular}

TABELA 19 - NÚMERO E PORCENTAGEM DE CRIANÇAS QUE JÁ HAVIAM INTRODUZIDO FEIJÃO NA DIETA, SEGUNDO IDADE E FREQÜÊNCIA SEMANAL DE CONSUMO NO ÚLTIMO MÊS.

\begin{tabular}{|c|c|c|c|c|c|c|c|c|}
\hline \multirow{3}{*}{$\begin{array}{l}\text { CONSUMO } \\
\text { DE FEIJÃO }\end{array}$} & \multicolumn{6}{|c|}{ DADE(dias) } & & \\
\hline & \multicolumn{2}{|c|}{$91-180$} & \multicolumn{2}{|c|}{$181=270$} & \multicolumn{2}{|c|}{$271-365$} & \multicolumn{2}{|c|}{ TOTAL } \\
\hline & $\mathrm{N}$ & $\%$ & $\mathrm{~N}$ & $\%$ & $\mathrm{~N}$ & $\%$ & $\mathrm{~N}$ & $\%$ \\
\hline DIÁRIO & 2 & 50,0 & 13 & 46,4 & 31 & 73,8 & 46 & 62,2 \\
\hline 2 A 6VEZES & 1 & 25,0 & 9 & 32,1 & 5 & 11,9 & 15 & 20,3 \\
\hline 1 VEZ OU MENOS & 1 & 25,0 & 4 & 14,3 & 4 & 9,5 & 95 & 12,2 \\
\hline NÃO CONSUMIU & 0 & - & 2 & 7,1 & 2 & 4,8 & 4 & 5,4 \\
\hline TOTAL & 4 & 100 & 28 & 100 & 42 & 100 & 74 & 100 \\
\hline
\end{tabular}

* não incluidas 2 crianças por falta de informação. 
TABELA 20 - NÚMERO E PORCENTAGEM DE CRIANÇAS QUE JÁ HAVIAM INTRODUZIDO FEIJÃO NA DIETA, SEGUNDO IDADE E CONSUMO NO DIA ANTERIOR

\begin{tabular}{cccccccccc}
\hline & \multicolumn{9}{c}{ IDADE (dias) } \\
\cline { 2 - 8 } CONSUMO & \multicolumn{2}{c}{$91-180$} & \multicolumn{2}{c}{$181-270$} & \multicolumn{2}{c}{$271-365$} & \multicolumn{2}{c}{ TOTAL } \\
DE FEIJÃO & $\mathrm{N}$ & $\%$ & $\mathrm{~N}$ & $\%$ & $\mathrm{~N}$ & $\%$ & $\mathrm{~N}$ & $\%$ \\
\hline SIM & 2 & 50,0 & 12 & 41,4 & 18 & 45,0 & 32 & 43.8 \\
NÃO & 2 & 50,0 & 17 & 58,6 & 22 & 55,0 & 41 & 56.2 \\
\hline TOTAL & 4 & 100 & 29 & 100 & 40 & 100 & 73 & 100 \\
\hline
\end{tabular}

* não incluidas 3 crianças por falta de informação

TABELA 21 - NÚMERO E PORCENTAGEM DE CRIANÇAS QUE JÁ HAVIAM INTRODUZIDO GEMA NA DIETA, SEGUNDO IDADE E FREQÜÊNCIA SEMANAL DE CONSUMO NO ÚLTIMO MÊS

\begin{tabular}{|c|c|c|c|c|c|c|c|c|c|c|}
\hline \multirow{3}{*}{$\begin{array}{l}\text { CONSUMO } \\
\text { DE GEMA }\end{array}$} & \multicolumn{8}{|c|}{ IDADE (dias) } & & \\
\hline & \multicolumn{2}{|c|}{$0-90$} & \multicolumn{2}{|c|}{$91-180$} & \multicolumn{2}{|c|}{$181-270$} & \multicolumn{2}{|c|}{$271-365$} & \multicolumn{2}{|c|}{ TOTAL } \\
\hline & $\mathrm{N}$ & $\%$ & $\mathbf{N}$ & $\%$ & $\mathbf{N}$ & $\%$ & $N$ & $\%$ & $\mathrm{~N}$ & $\%$ \\
\hline DIÁRIO & 1 & 100 & 5 & 23,8 & 7 & 14,6 & 6 & 11,1 & 19 & 15,3 \\
\hline 2 A 6 VEZES & 0 & - & 9 & 42,9 & 25 & 52,1 & 23 & 42,6 & 57 & 46,0 \\
\hline $1 \mathrm{VEZ} \mathrm{OU} \mathrm{-}$ & 0 & - & 6 & 28,6 & 15 & 31,3 & 21 & 38,9 & 42 & 33,9 \\
\hline NÃO CONS. & 0 & - & 1 & 4,8 & 1 & 2,0 & 4 & 7,4 & 6 & 4,8 \\
\hline TOTAL & 1 & 100 & 21 & 100 & 48 & 100 & 54 & 100 & 124 & 100 \\
\hline
\end{tabular}

* não incluídas 6 crianças por falta de informação. 
TABELA 22 - NÚMERO E PORCENTAGEM DE CRIANÇAS QUE JÁ HAVIAM INTRODUZIDO GEMA NA DIETA, SEGUNDO IDADE E CONSUMO NO DIA ANTERIOR

\begin{tabular}{cccccccccccc}
\hline & \multicolumn{10}{c}{ IDADE (dias) } & \multicolumn{1}{c}{ TOTAL } \\
\cline { 2 - 10 } CONSUMO & \multicolumn{2}{c}{$0-90$} & \multicolumn{1}{c}{$91-180$} & $181-270$ & $271-365$ & \multicolumn{2}{c}{ TOT } \\
DE GEMA & $\mathrm{N}$ & $\%$ & $\mathrm{~N}$ & $\%$ & $\mathrm{~N}$ & $\%$ & $\mathrm{~N}$ & $\%$ & $\mathrm{~N}$ & $\%$ \\
\hline SIM & 1 & 100 & 3 & 14,3 & 10 & 20,4 & 6 & 11,1 & 20 & 16,0 \\
NÃO & 0 & - & 18 & 85.7 & 39 & 79.6 & 48 & 88.9 & 105 & 84,0 \\
\hline TOTAL & 1 & 100 & 21 & 100 & 49 & 100 & 54 & 100 & 125 & 100 \\
\hline
\end{tabular}

*não incluídas 5 crianças por falta de informação.

TABELA 23 - NÚMERO E PORCENTAGEM DE CRIANÇAS QUE JÁ HAVIAM INTRODUZIDO HORTALIÇAS DE FOLHA NA DIETA, SEGUNDO IDADE E FREQÜÊNCIA SEMANAL DE CONSUMO NO ÚLTIMO MÊS

\begin{tabular}{|c|c|c|c|c|c|c|c|c|}
\hline \multirow{3}{*}{$\begin{array}{l}\text { CONSUMO DE } \\
\text { HORTALIÇAS }\end{array}$} & \multicolumn{6}{|c|}{ IDADE(dias) } & & \\
\hline & \multicolumn{2}{|c|}{$91-180$} & \multicolumn{2}{|c|}{$181-270$} & \multicolumn{2}{|c|}{$271-365$} & \multicolumn{2}{|c|}{ TOTAL } \\
\hline & $\mathrm{N}$ & $\%$ & $\mathrm{~N}$ & $\%$ & $\mathrm{~N}$ & $\%$ & $\mathrm{~N}$ & $\%$ \\
\hline DIÁRIO & 17 & 81,0 & 26 & 65,0 & 25 & 56,8 & 68 & 64,8 \\
\hline 2 a 6 VEZES & 3 & 14,3 & 10 & 25,0 & 12 & 27,3 & 25 & 23,8 \\
\hline $1 \mathrm{VEZ} \mathrm{OU} \mathrm{-}$ & 1 & 4,8 & 3 & 7,5 & 6 & 13,6 & 10 & 9,5 \\
\hline NÃO CONS. & - & - & 1 & 2,5 & 1 & 2,3 & 2 & 1,9 \\
\hline TOTAL & 21 & 100 & 40 & 100 & 44 & 100 & 105 & 100 \\
\hline
\end{tabular}

* não incluidas 5 crianças por falta de informação. 
TABELA-24 - NÚMERO E PORCENTAGEM DE CRIANÇAS QUE JÁ HAVIAM INTRODUZIDO HORTALIÇAS DE FOLHA NA DIETA, SEGUNDO IDADE E CONSUMO NO DIA ANTERIOR

\begin{tabular}{|c|c|c|c|c|c|c|c|c|}
\hline \multirow{3}{*}{$\begin{array}{l}\text { CONSUMO DE } \\
\text { HORTALICCAS }\end{array}$} & \multicolumn{6}{|c|}{ IDADE (dias) } & & \\
\hline & \multicolumn{2}{|c|}{$91-180$} & \multicolumn{2}{|c|}{$181-270$} & \multicolumn{2}{|c|}{$271-365$} & \multicolumn{2}{|c|}{ TOTAL } \\
\hline & $\mathrm{N}$ & $\%$ & $\mathrm{~N}$ & $\%$ & $\mathrm{~N}$ & $\%$ & $\mathrm{~N}$ & $\%$ \\
\hline SIM & 10 & 47,6 & 17 & 40,5 & 15 & 34.1 & 42 & 39.3 \\
\hline NÃO & 11 & 52.4 & 25 & 59.5 & 29 & 65.9 & 65 & 60.7 \\
\hline TOTAL* & 21 & 100 & 42 & 100 & 44 & 100 & 107 & 100 \\
\hline
\end{tabular}

*não incluidas 3 crianças por falta de informação

Ao analisar a freqüência semanal de consumo dos alimentos não lácteos juntamente com a ingestão no dia anterior, alguns aspectos chamam a atenção. Em relação a frutas, foi elevada a proporção de crianças para as quais foi referido o consumo diário - 73\% - (tabela 15). Isso mostra que, além de ser, geralmente, o primeiro alimento introduzido, é o mais consumido, talvez pela boa aceitação, facilidade na oferta e reconhecimento de que é alimento importante no fornecimento de vitaminas.

- consumo diário de carne foi referido para $67,6 \%$ das crianças (tabela 17).

As tabelas 16 e 18, que apresentam a ingestão de frutas e carne, respectivamente, no dia anterior, mostram a consistência desses dados, pois as proporções de crianças que haviam consumido esses alimentos são muito próximas às observadas para a freqüencia diária.

o mesmo não aconteceu em relação a feijão e hortaliças. Para 73,8\% das crianças com idades entre 9 e 12 meses foi referido consumo diário de feijão no último mês, enquanto que apenas 45\% dessas crianças haviam recebido esse alimento no dia anterior 
(tabelas 19 e 20). Em relação a hortaliças, diferenças nesse mesmo sentido foram encontradas para crianças dos três grupos etários (tabelas 23 e 24).

Em relação à gema, verifica-se que mais de $80 \%$ das crianças, em todas as faixas etárias, não a haviam recebido no dia anterior, o que é compatível com a frequiência de consumo semanal observada (tabelas 21 e 22). 
4.3.ANEMIA, IDADE, PESO AO NASCER E PESO ATUAL

A influência da idade na determinação da anemia é apresentada na tabela 25.

TABELA 25 - NÚMERO E PORCENTAGEM DE CRIANÇAS, SEGUNDO IDADE E ANEMIA.

\begin{tabular}{|c|c|c|c|c|c|c|}
\hline \multirow{3}{*}{ ANEMIA } & \multicolumn{4}{|c|}{ IDADE (dias) } & & \\
\hline & \multicolumn{2}{|c|}{$1-180$} & \multicolumn{2}{|c|}{$181-365$} & \multicolumn{2}{|c|}{ TOTAL } \\
\hline & $\mathrm{N}$ & $\%$ & $\mathrm{~N}$ & $\%$ & $\mathrm{~N}$ & $\%$ \\
\hline ANÊMICO & 16 & 8,7 & 30 & 22,4 & 46 & 14,5 \\
\hline N.ANÊMICO & 167 & 91.3 & 104 & 77,6 & 271 & 85.5 \\
\hline TOTAL & 183 & 100 & 134 & 100 & 317 & 100 \\
\hline
\end{tabular}

Verifica-se que, quando a população estudada é dividida em dois grupos etários, a prevalência de anemia aumenta muito no segundo semestre de vida $(22,4 \%)$. Os valores observados são muito menores que os encontrados no município de São Paulo, em 19841985, quando foram verificadas as prevalências de 34,7\% para crianças entre 0-6 meses de idade e 53,7\% para crianças entre 6-12 meses de idade ${ }^{31}$.

A menor prevalência de anemia encontrada no presente estudo, talvez, seja devida ao fato de se tratar de grupo com características diferentes da população do município de São Paulo como um todo. Os quatro serviços estudados localizam-se em regiões centrais, longe, portanto, das zonas periféricas do município, onde se encontram aqueles que têm piores condições sociais, econômicas e de saúde. 
Depoimentos de profissionais que atuam nos CSEs mostraram que grande parte dos moradores das favelas das regiões não frequientam os servicos, sendo trabalhados por grupos de vigilância epidemiológica, que vão até essas populações. Isso permite levantar a hipótese de que o acesso a esses CSEs seja, de certa forma, seletivo.

A baixa prevalência de anemia encontrada, talvez seja devida ao fato dessa população estar frequentando regularmente o programa de puericultura, na maior parte das vezes, na mesma instituição onde as mães fizeram pré-natal. Possivelmente, a continuidade no atendimento materno-infantil tenha favorecido a situação de saúde da criança.

Os resultados obtidos devem ser analisados sem perder de vista o fato de que a concentração de $\mathrm{Hb}$ nos primeiros 180 dias de vida, apresenta grande variação. Ela é elevada nos primeiros 15 a 20 dias, atingindo $16-17 \mathrm{~g} / \mathrm{dl}$, diminuindo, a partir dai, gradativamente, até valores próximos a $11-12 \mathrm{~g} / \mathrm{dl}$, ao redor dos 6 meses de vida ${ }^{9}$. Esse aspecto dificulta o diagnóstico de anemia na criança com menos de 180 dias, considerando-se, principalmente, a inexistência de valores criticos de $\mathrm{Hb}$, especificos para cada idade. Em vista disso, adotaram-se como referência os valores médios de $\mathrm{Hb}$ encontrados por Brault-Dubuc ${ }^{2}$ em estudo longitudinal de população sadia. A curva de concentrações médias de Hb encontrada na população amostral é apresentada no gráfico 1. 


\section{GRÁFICO 1 - MÉDIAS DAS CONCENTRAÇÕES DE HEMOGLOBINA EM CRIANÇAS MENORES DE UM ANO}

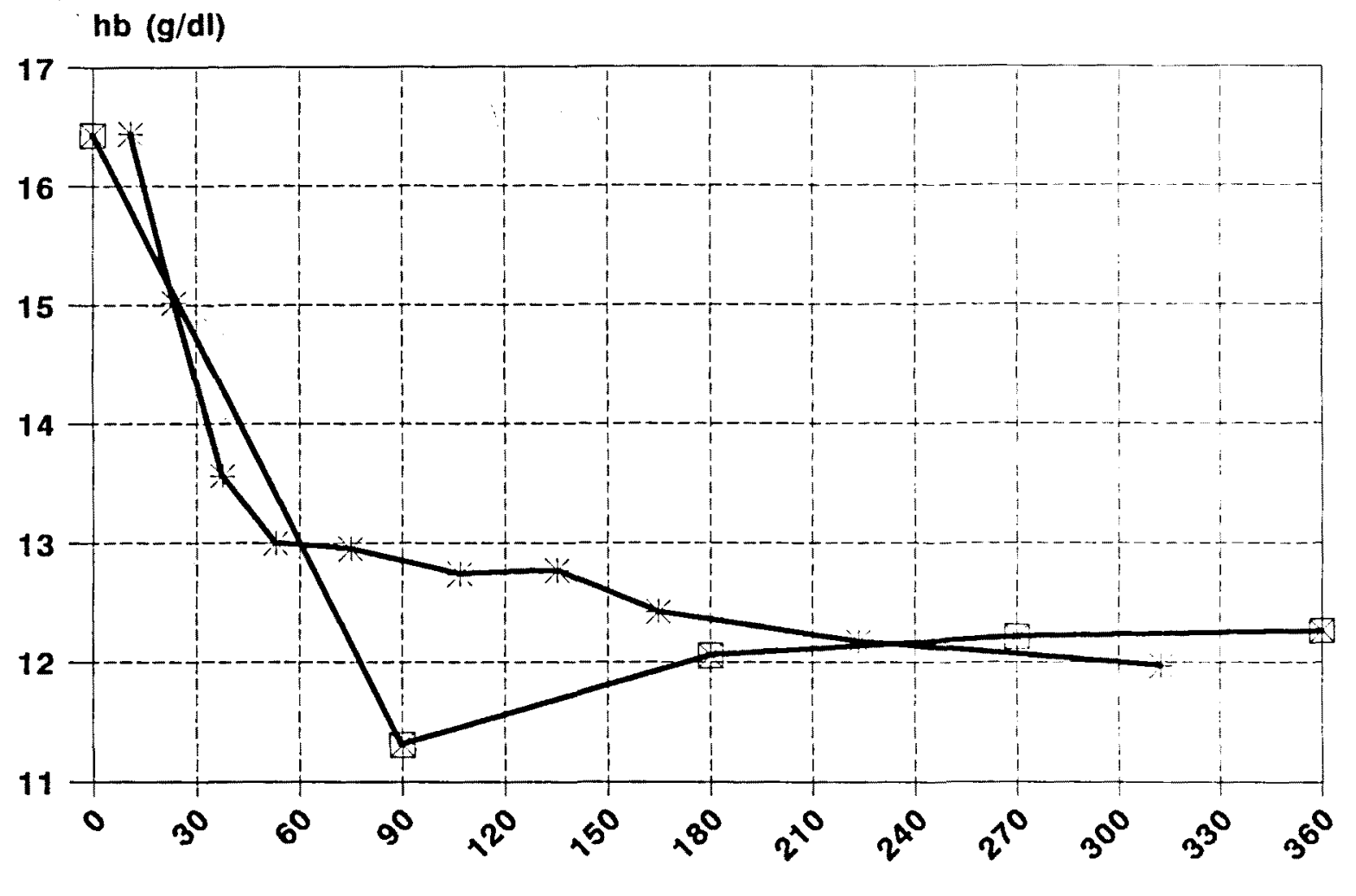

Idade em dias

$\triangle$ Padrao (Brault-Dubuc) $*$ Este estudo

Comparando-se a curva das crianças da amostra com a padrão, verifica-se um declínio da primeira pouco mais acentuado até aproximadamente 60 dias de vida. A partir dai, até por volta de 180 dias, os valores médios de concentração de $\mathrm{Hb}$, nas crianças da amostra, mantiveram-se sempre acima de 12g/dl e sempre acima do padrão. Entretanto, enquanto a curva padrão, a partir de 90 dias, mostra uma tendência ascendente, a curva da amostra apresentou inclinação descendente, levando a supor que, no segundo ano de vida, essas crianças venham a apresentar valores médios de $\mathrm{Hb}$, provavelmente inferiores aos do padrão. 
Essas condições também se evidenciaram no grupo das 31 crianças da amostra nascidas com baixo peso.

Quando os valores individuais de $\mathrm{Hb}$ dessas criancas são cotejados com os valores do padrão Brault-Dubuc ${ }^{2}$ (gráfico 2), nota-se que a distribuição é semelhante à verificada para a população em geral (gráfico 1), diferindo por apresentar, nos dois primeiros meses de vida, valores abaixo do padrão, como esperado.

\section{GRÁFICO 2 - CONCENTRAÇÕES DE HEMOGLOBINA EM CRIANÇAS MENORES DE UM ANO COM BAIXO PESO AO NASCER}

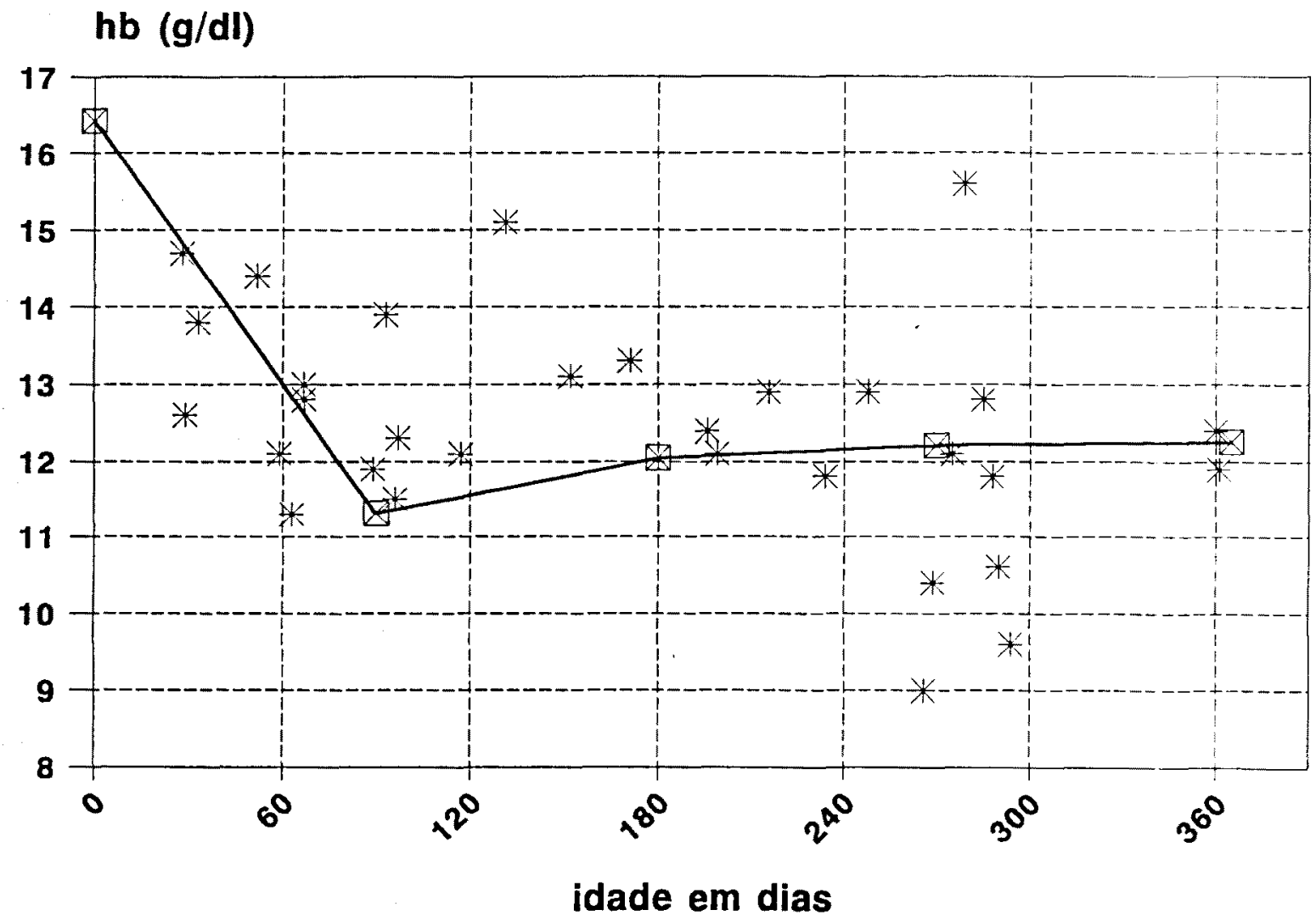

Padrão (Brault-Dubuc) $*$ Este estudo

Em relação à adequação do peso atual, as crianças da amostra foram comparadas, quanto ao indice peso/idade, com o 
padrão NCHS ${ }^{20}$. Os resultados são apresentados no gráfico 3, mostrando que a distribuição encontrada está muito próxima do padrão, com uma concentração um pouco menor à direita. Essa adequação, embora tenha sido utilizado um único parâmetro, permite inferir, de certa forma, que as crianças estudadas tinham estado nutricional semelhante ao da população padrão.

\section{GRÁFICO 3 - COMPARAÇÃO DAS CRIANÇAS ESTUDADAS COM O PADRÃO NCHS. ÍNDICE PESO/IDADE}

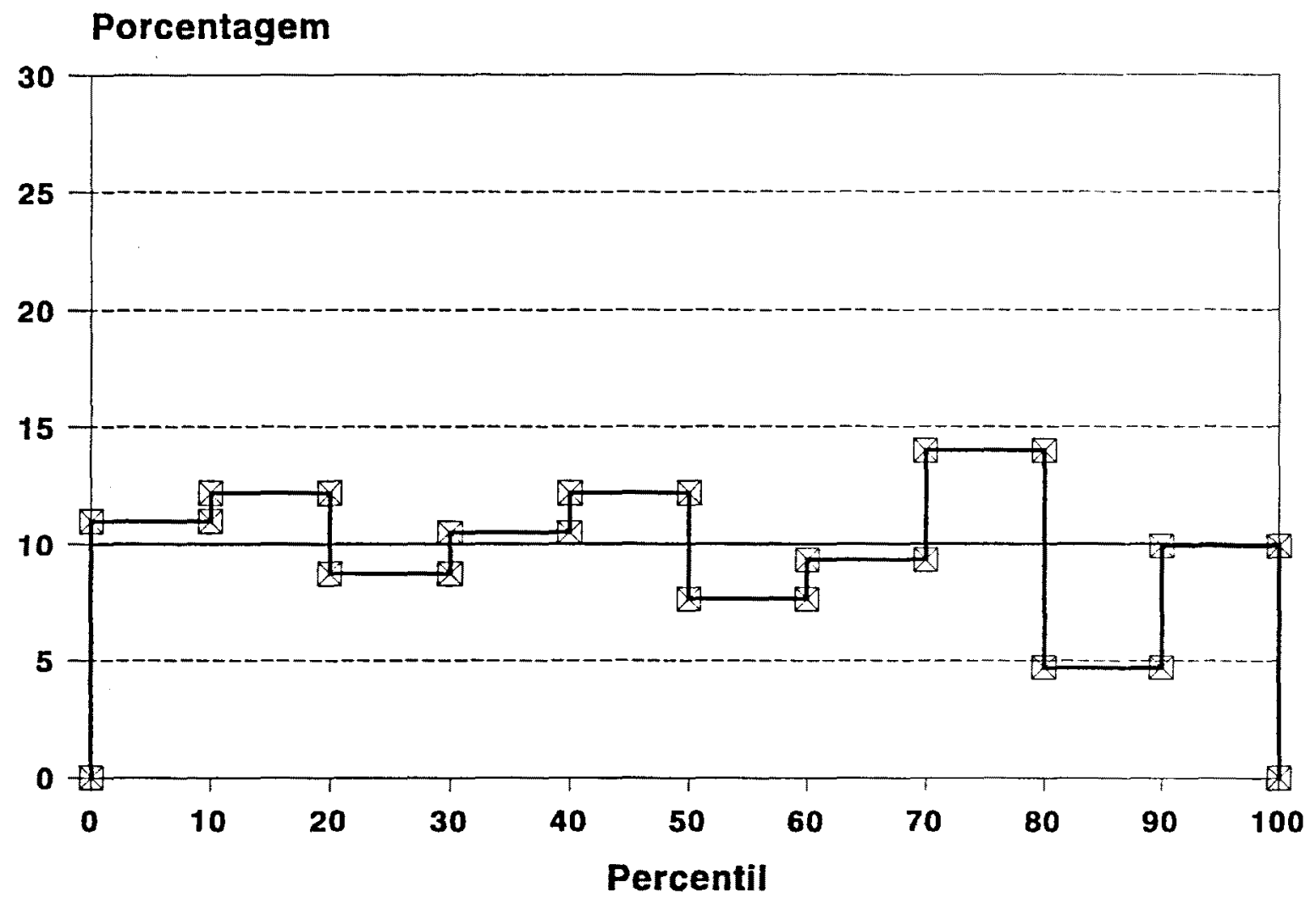

- Referência $\forall$ Estudo 
4.4.ANEMIA E DURAÇÃO DO ALEITAMENTO MATERNO

o gráfico 4 mostra as curvas de duração do aleitamento materno exclusivo para crianças anêmicas e não anêmicas.

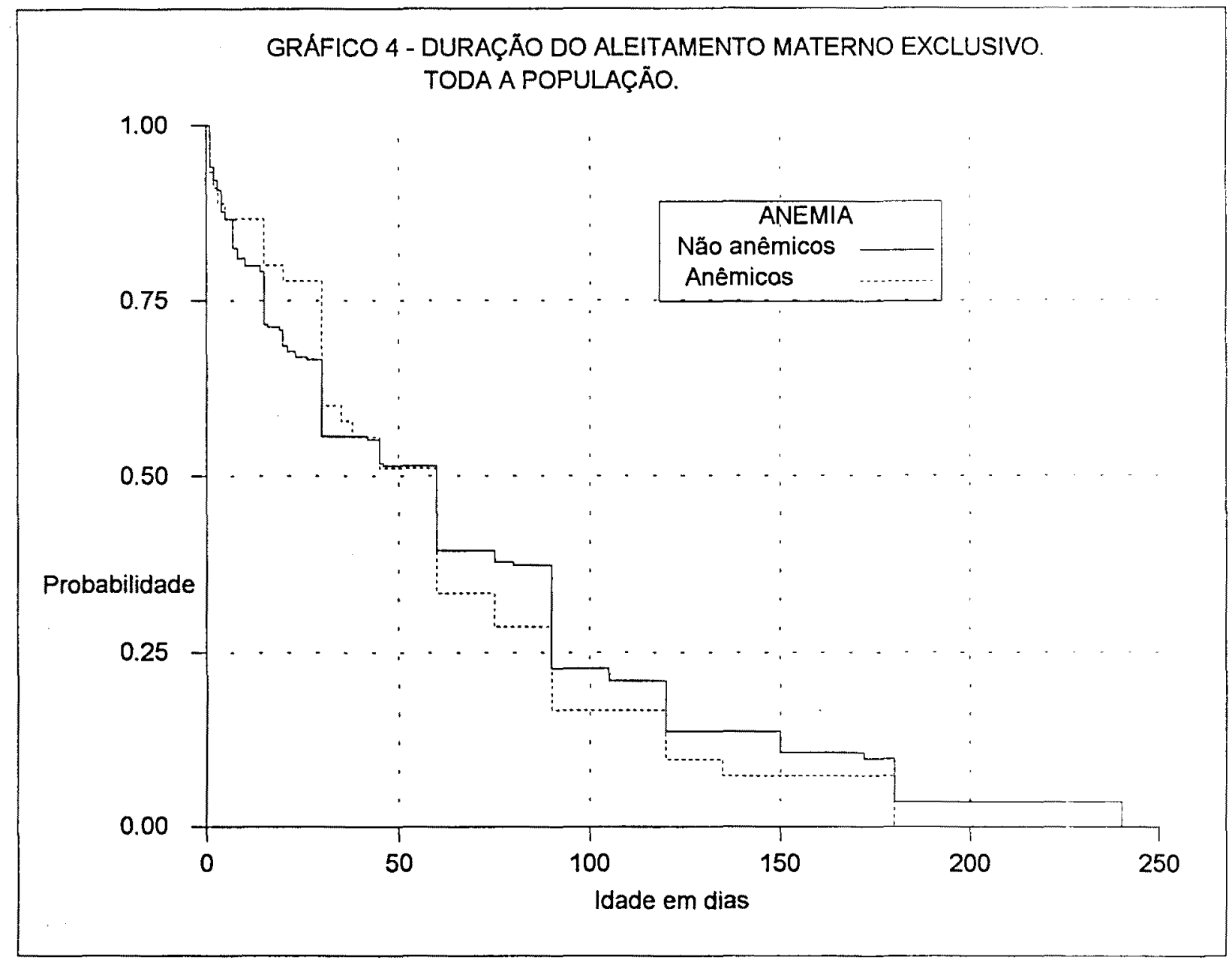

As curvas são iniciadas com a totalidade das crianças em aleitamento materno exclusivo dos dois grupos. A proporção de crianças vai diminuindo à medida que ocorre o evento "introdução de alimentos ",e prossegue até que a última criança em observação introduza o primeiro alimento. As crianças que, no momento da observação, ainda estavam em aleitamento materno exclusivo, cons- 
tituem os dados censurados, pois não se sabe o que aconteceu com elas depois da observação.

A duração mediana do aleitamento materno exclusivo para anêmicos e não anêmicos foi de 60 dias. As diferenças verificadas entre as curvas não são estatisticamente significantes $\left(\chi^{2}=0,36\right.$; $\mathrm{p}=0,55)$.

Considerando-se a importância do aleitamento materno exclusivo nos primeiros 6 meses de vida e que o possível efeito de proteção do mesmo, provavelmente, reflita-se a partir dessa idade, avaliou-se, entre as crianças com mais de 180 dias, o papel dessa prática alimentar na ocorrência da anemia, que é mais prevalente nessa faixa etária (gráfico 5).

As diferenças verificadas entre os grupos de anêmicos e de não anêmicos, com idades acima de 6 meses, não são estatisticamente significantes $\left(\chi^{2}=0,35 ; \mathrm{p}=0,55\right)$. Nota-se que as curvas obtidas são muito semelhantes às encontradas para a população total (gráfico 4) e que o tempo mediano de duração do aleitamento materno exclusivo foi, também, de 60 dias, para os dois grupos.

A mediana encontrada pode ser considerada baixa, evidenciando o desmame precoce, mas é próxima à verificada no município de São Paulo, em 1984-85 - 62,85 dias30 - . 


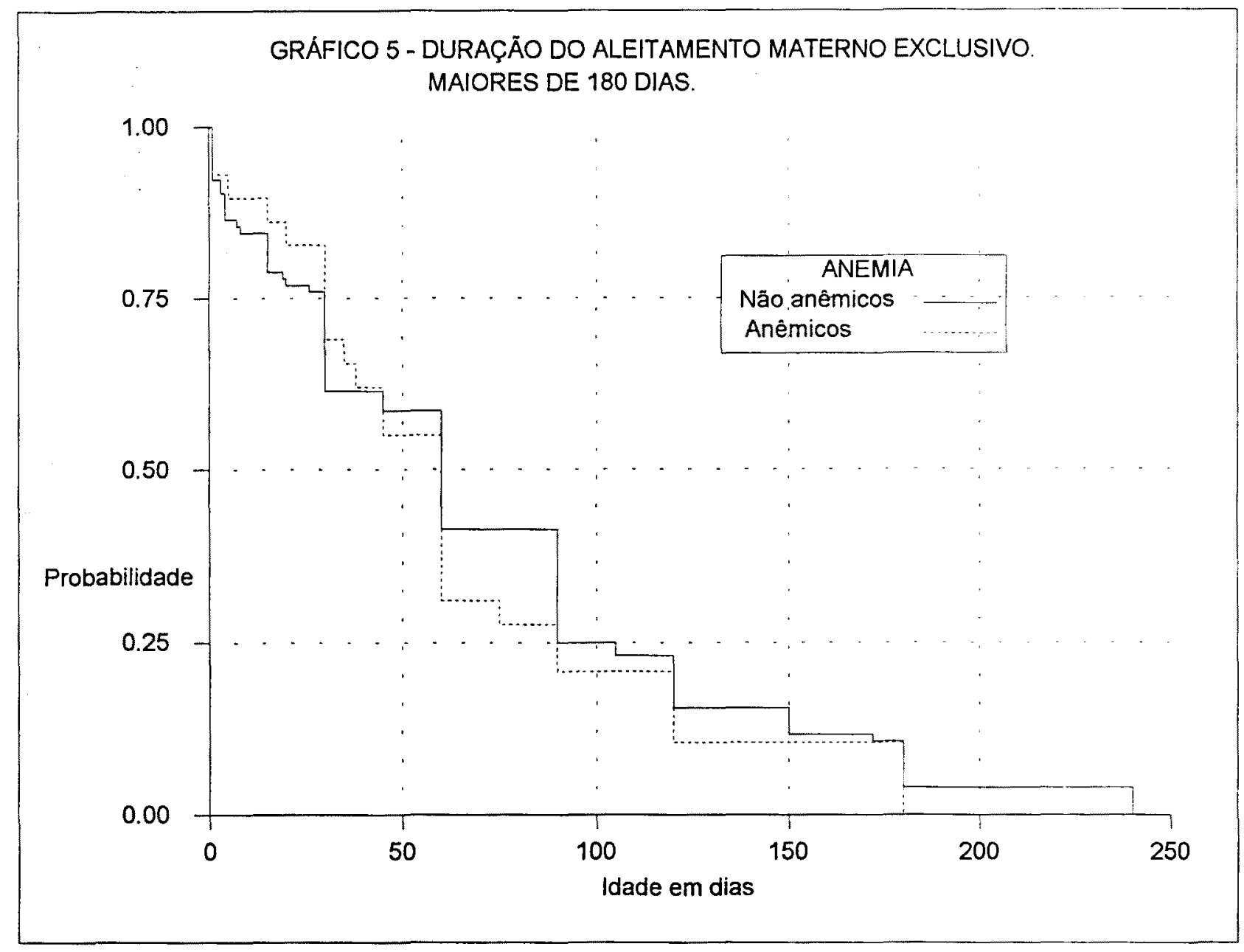

- gráfico 6 mostra a duração do aleitamento materno total, para os dois grupos. A duração mediana foi de 120 dias para anêmicos e não anêmicos. As diferenças verificadas entre as curvas não são estatisticamente significantes $\left(\chi^{2}=0,00 ; p=0,99\right)$.

A mediana de duração do aleitamento total verificada no presente estudo é maior que a observada em duas outras pesquisas: em 1973-74, em estudo epidemiológico, no município de São Paulo, a mediana foi de apenas $28 \operatorname{dias}^{49}$; em estudo longitudinal de crianças nascidas em três maternidades que atendem população de baixa renda, no município de São Paulo, em 1981, foi verificada a duração mediana de 2 meses e 7 dias $^{48}$. 
GRAFICO 6 - DURAÇÃO DO ALEITAMENTO MATERNO TOTAL

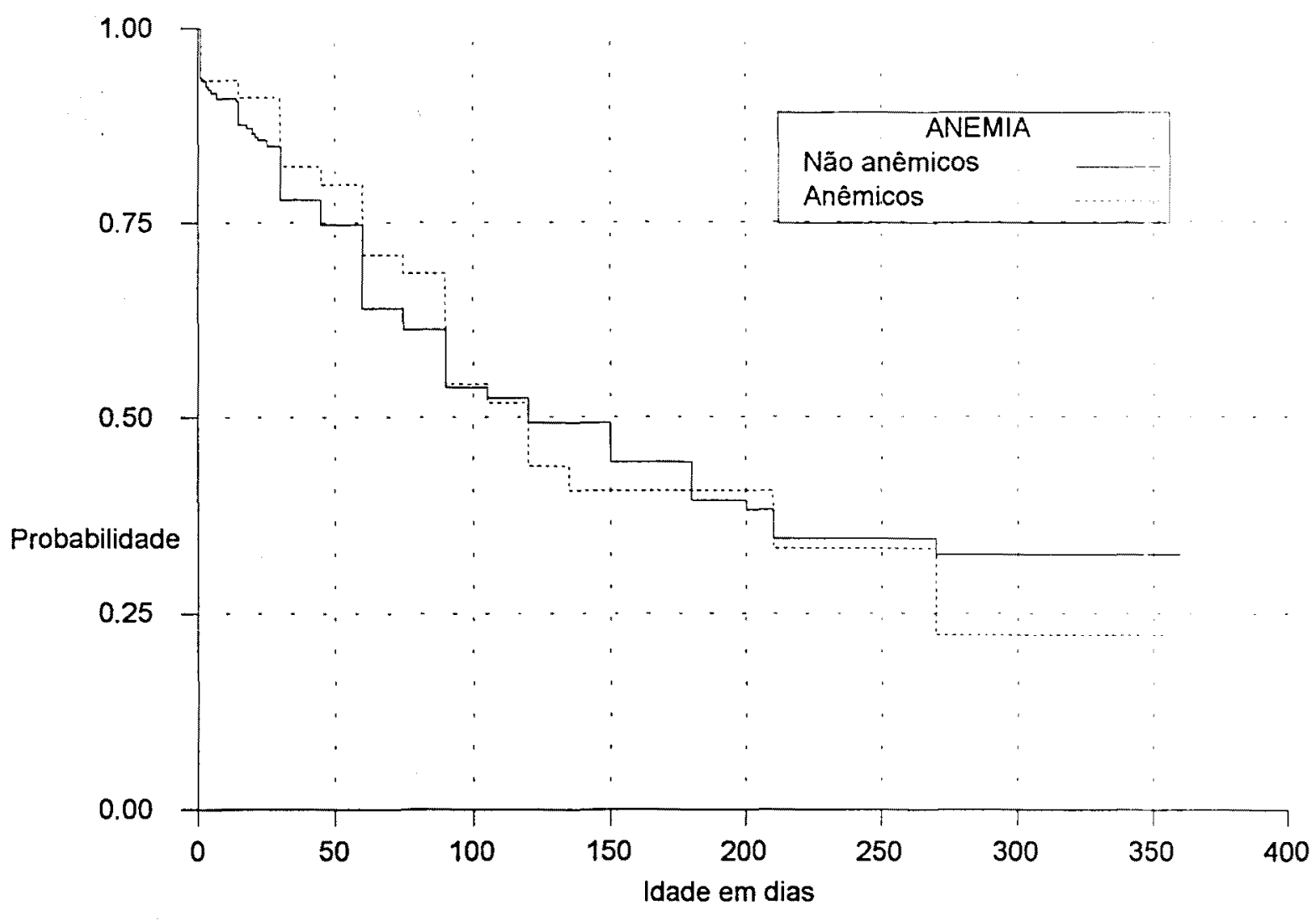

Em pesquisa mais recente (1989), os pesquisadores observaram, em familias residentes em área atendida pelo CSE2, a mediana de duração do aleitamento total de 84 dias²3. Em 1990, em serviços de atenção primária à saúde, no município de Pelotas, no Rio Grande do Sul, verificou-se a mesma mediana deste estudo - 4 meses 34 - .

Sendo a alimentação no primeiro ano de vida predominantemente láctea, e tendo sido verificado que a idade média de introdução de outros leites foi 1,7 meses, pressupõe-se que 0 desmame se inicie com essa introdução e que o leite, talvez mais que outros alimentos, esteja associado ao aparecimento da anemia nessa fase da vida. Assim, foram elaboradas as curvas de duração do aleitamento materno, segundo a ocorrência da anemia, conside- 
rando-se apenas a introdução de leites e não de outros alimentos, que poderiam ou não estar sendo consumidos pelas criancas.

As curvas obtidas são apresentadas nos gráficos 7 (todas as crianças) e 8 (crianças maiores de 180 dias).

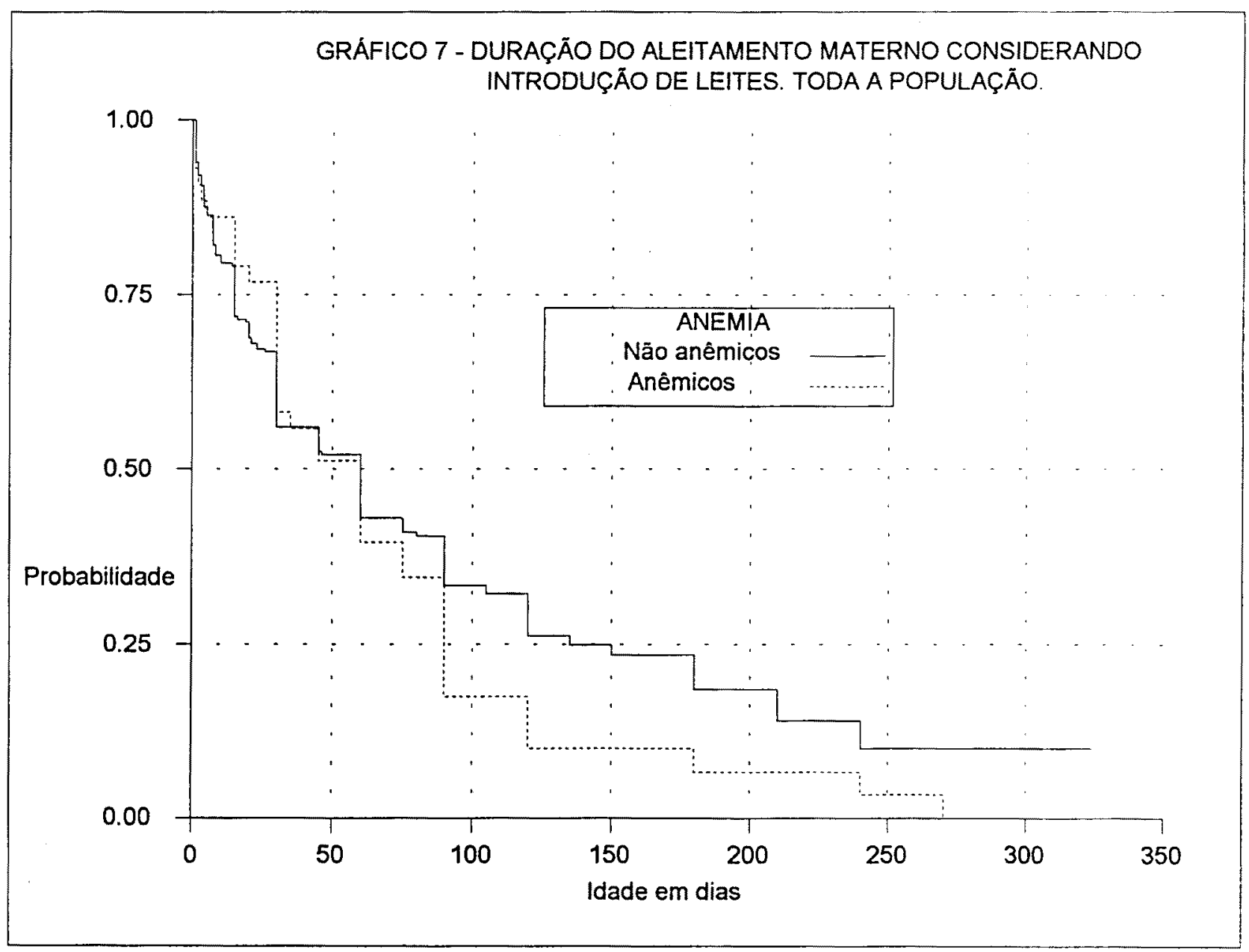




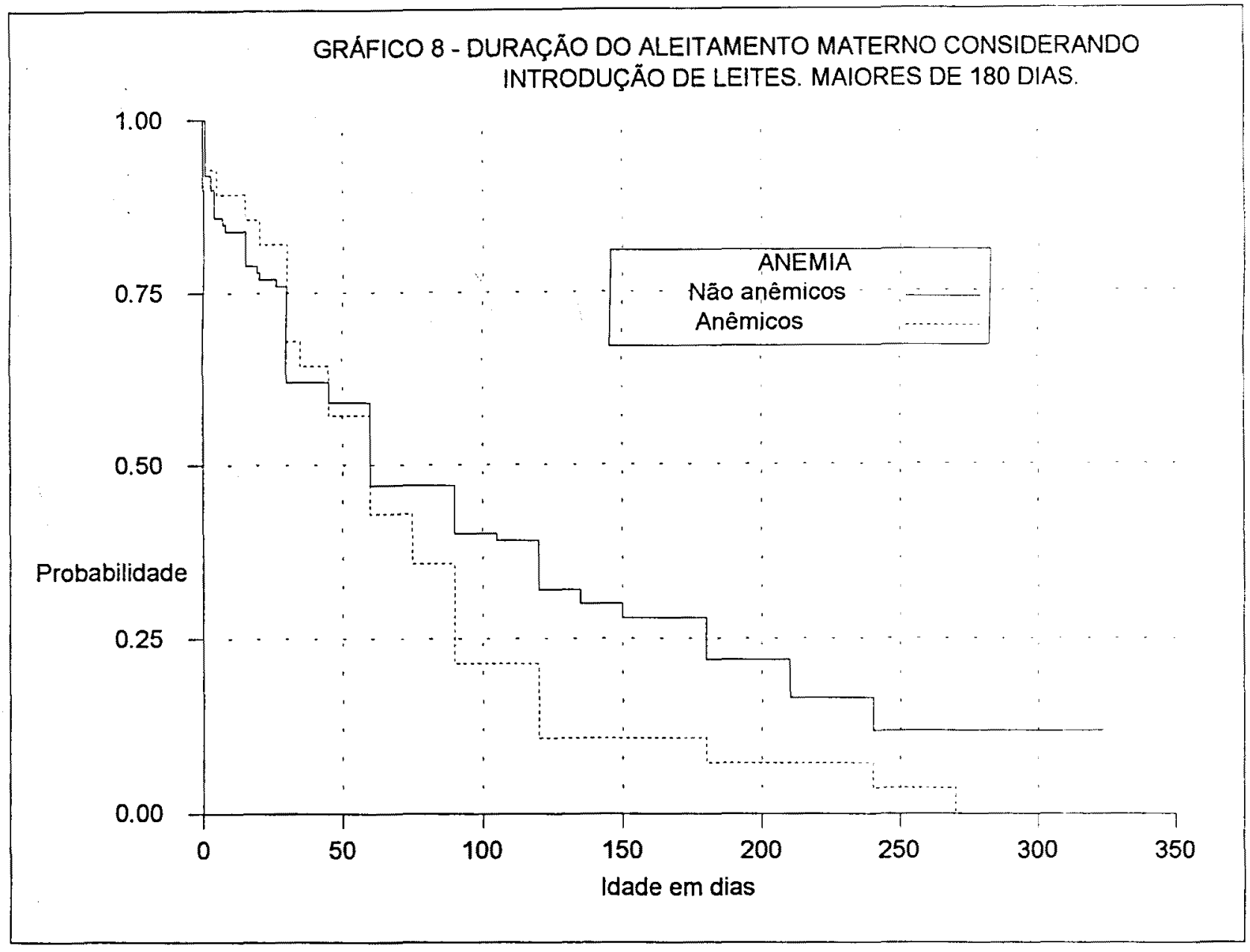

Verifica-se, em ambos, mas de forma mais acentuada no gráfico 8, que as curvas se separam a partir de 3 a 4 meses de vida, com maior declínio da referente às crianças anêmicas. Esses resultados sugerem que, até 3 meses de idade, quando as curvas praticamente se sobrepõem, a anemia, além de pouco prevalente, não estava associada ao aleitamento materno. Entre o terceiro e o quarto meses de vida, quando a criança passa a depender mais do aporte alimentar de ferro para suprir suas necessidades, verificase a associação com o aleitamento, embora não estatisticamente significante (gráfico $7: \chi^{2}=1,64-p=0,20$; gráfico 8 : $\chi^{2}=$ $1,64-p=0,20)$. 
A mediana de duração do aleitamento, tanto para crianças de todas as idades como para as maiores de 6 meses, anêmicas ou não, manteve-se em 60 dias. Entretanto, os valores para o terceiro quartil foram diferentes. Para crianças de todas as idades, os terceiros quartis foram 90 dias para anêmicas e 135 dias para não anêmicas, enquanto entre as maiores de 180 dias, os valores foram 92 dias para anêmicas e 180 dias para não anêmicas.

Tendo em vista que as diferenças entre os dois grupos, conforme observado, surgiram entre o terceiro e o quarto meses de vida, verificaram-se, entre as crianças com mais de 180 dias, a situação do aleitamento na idade de 4 meses e sua relação com a anemia. Os resultados são apresentados na tabela 26.

\section{TABELA 26 - NÚMERO E PORCENTAGEM DE CRIANÇAS MAIORES DE 180 DIAS, SEGUNDO SITUAÇÃO DE ALEITAMENTO AOS 4 MESES E ANEMIA}

\begin{tabular}{|c|c|c|c|c|c|c|}
\hline \multirow[b]{3}{*}{ ANEMIA } & \multicolumn{4}{|c|}{ ALEITAMENTO } & & \\
\hline & \multicolumn{2}{|c|}{ LEITE MATERNO } & \multicolumn{2}{|c|}{ OUTROS LEITES } & \multicolumn{2}{|c|}{ TOTAL } \\
\hline & $\mathrm{N}$ & $\%$ & $\mathrm{~N}$ & $\%$ & $\mathrm{~N}$ & $\%$ \\
\hline SIM & 3 & 8,6 & 25 & 26,9 & 28 & 21,9 \\
\hline NÃO & 32 & 91.4 & 68 & 73.1 & 100 & 78.1 \\
\hline \multirow[t]{2}{*}{ TOTAL * } & 35 & 100 & 93 & 100 & 128 & 100 \\
\hline & icol & & $\chi^{2}=4,99$ &, 025 & & \\
\hline
\end{tabular}

Entre as crianças cujo único tipo de leite ingerido era - materno, encontraram-se $8,6 \%$ de anêmicas; entre aquelas que tomavam outros leites, essa proporção chegou a 26,98 , sendo a diferença entre os dois grupos estatisticamente significante. 
Os resultados encontrados permitem supor que a proteção dada pelo leite materno se mantém, mesmo quando alimentos não Iácteos estão presentes na dieta da criança.

4.5.ANEMIA E INTRODUÇÃO DE DIFERENTES TIPOS DE LEITE

Tendo em vista que $47,2 \%$ das crianças receberam leite formulado no início do aleitamento misto ou artificial (tabela 11), verificou-se se a associação com a anemia se altera conforme - tipo de leite utilizado. A tabela 27 mostra os resultados encontrados.

\section{TABELA 27 - DISTRIBUIÇÃO DAS CRIANÇAS, SEGUNDO TIPO DE LEITE NA INTRODUÇÃO DE MAMADEIRA E ANEMIA}

\begin{tabular}{cccccccccc}
\hline & \multicolumn{7}{c}{ TIPO DE LEITE } & \multicolumn{2}{c}{} \\
\cline { 2 - 8 } ANEMIA & \multicolumn{2}{c}{ FLUIDO } & \multicolumn{2}{c}{ INTEGRAL } & \multicolumn{2}{c}{ FORMULADO } & \multicolumn{2}{c}{ TOTAL } \\
& $\mathrm{N}$ & $\%$ & $\mathrm{~N}$ & $\%$ & $\mathrm{~N}$ & $\%$ & $\mathrm{~N}$ & $\%$ \\
\hline ANÊMICO & 7 & 20,0 & 17 & 19,8 & 17 & 15,7 & 41 & 17,9 \\
NÃO.ANÊMICO & 28 & 80,0 & 69 & 80,2 & 91 & 84,3 & 188 & 82,1 \\
\hline TOTAL & 35 & 100 & 86 & 100 & 108 & 100 & 229 & 100 \\
\hline \multicolumn{3}{c}{$\chi^{2}$ crítico $(2 \mathrm{gl})=5,99$} & \multicolumn{3}{c}{$\chi^{2}=0,65$} & $\mathrm{p}=0,7219$ & &
\end{tabular}

Entre as crianças que receberam leites formulados, a proporção de anêmicas é próxima à encontrada para os outros grupos. A diferença não é estatisticamente significante.

Tem sido verificado que a utilização de fórmulas enriquecidas com ferro previne a anemia em crianças que não estão em aleitamento materno, ou quando introduzidas no início do des- 
mame $5,7,18,58$. Possivelmente, o alto custo desses leites não permitiu o seu uso por periodo suficiente para manter os estoques marciais.

4.6. ANEMIA E INTRODUÇÃO DE ALIMENTOS NÃO LÁCTEOS

Os gráficos de 9 a 13 mostram, para crianças anêmicas e não anêmicas, as curvas das idades de introdução dos alimentos não lácteos, importantes na determinação da anemia (frutas, carnes, feijào hortaliças de folha), e também da gema de ovo.

Em relação a frutas, não se fez distinção de tipos (laranja, maçã, banana, etc.) e formas de ingestão (sucos, papas, cremes, etc.).

Verifica-se, no gráfico 9, que as curvas de sua introdução na alimentação, para anêmicos ou não, praticamente se superpõem, evidenciando a semelhança entre os dois grupos $\left(\chi^{2}=0,11 \mathrm{p}\right.$ $=0,74)$. A idade mediana de introdução de frutas foi de 120 dias para ambos. 


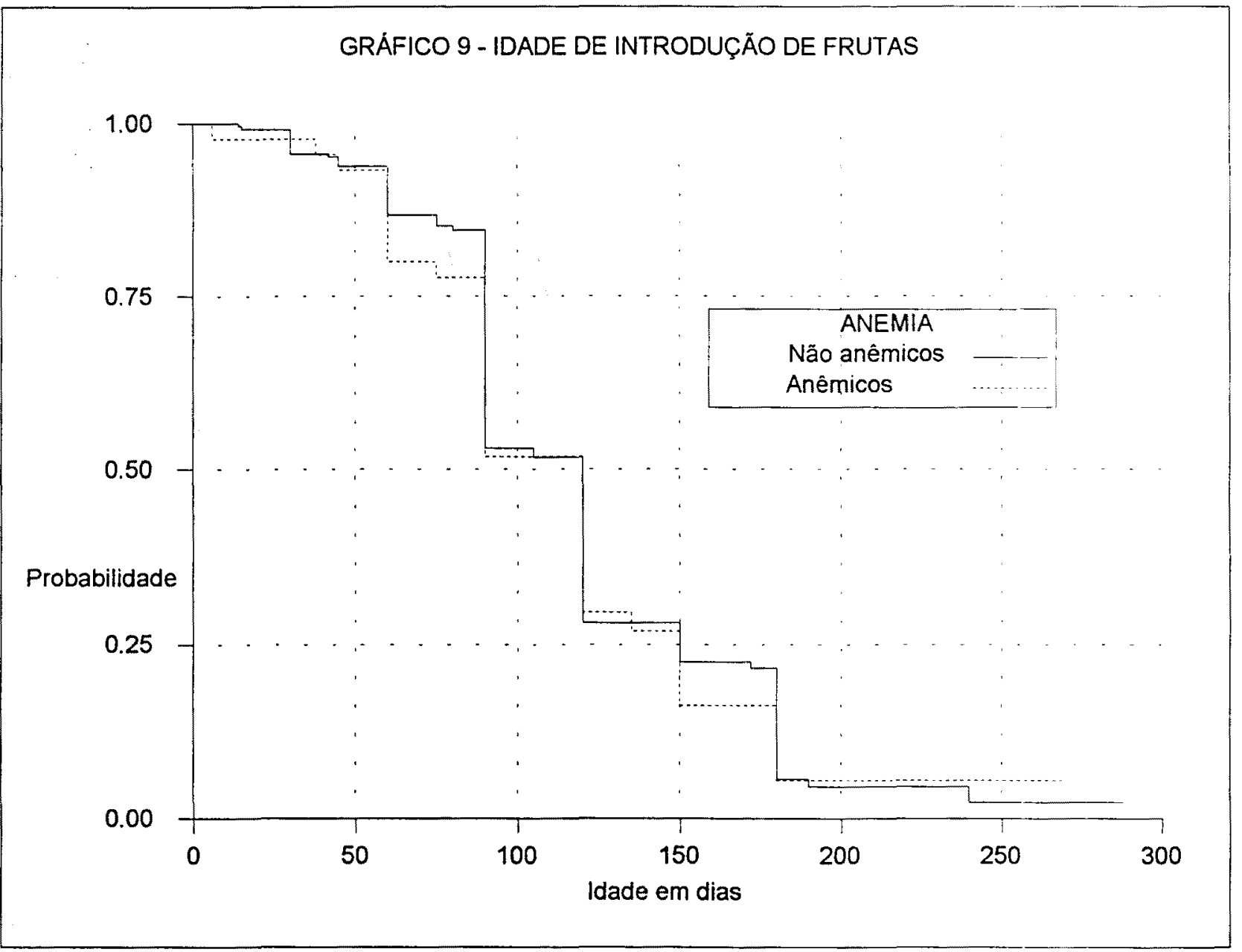

Quanto à introdução de carnes, as curvas para os dois grupos (gráfico 10) são também muito semelhantes, mostrando que a época de introdução desse alimento não está associada com anemia $\left(\chi^{2}=0,03 \mathrm{p}=0,87\right)$. A idade mediana de introdução foi de 150 dias para os dois grupos. 


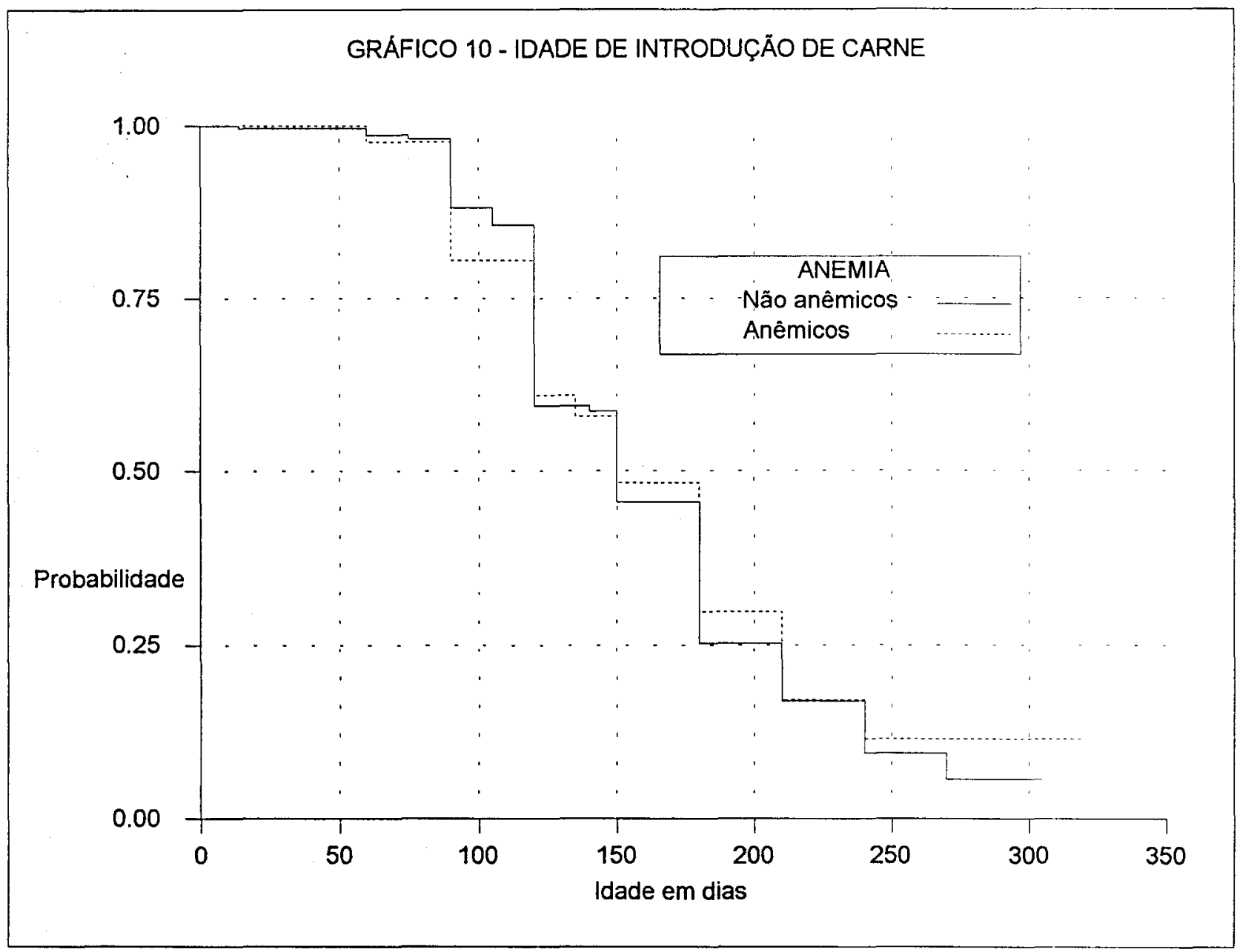

A introdução de feijão na alimentação é apresentada no gráfico 11. As curvas dos dois grupos apresentam diferenças que não são estatisticamente significantes $\left(\chi^{2}=1,40 \quad p=0,24\right)$.

Verifica-se que as crianças anêmicas fizeram introdução mais tardia de feijão na alimentação, com idade mediana de 300 dias, enquanto a mediana para os não anêmicos foi de 240 dias. 


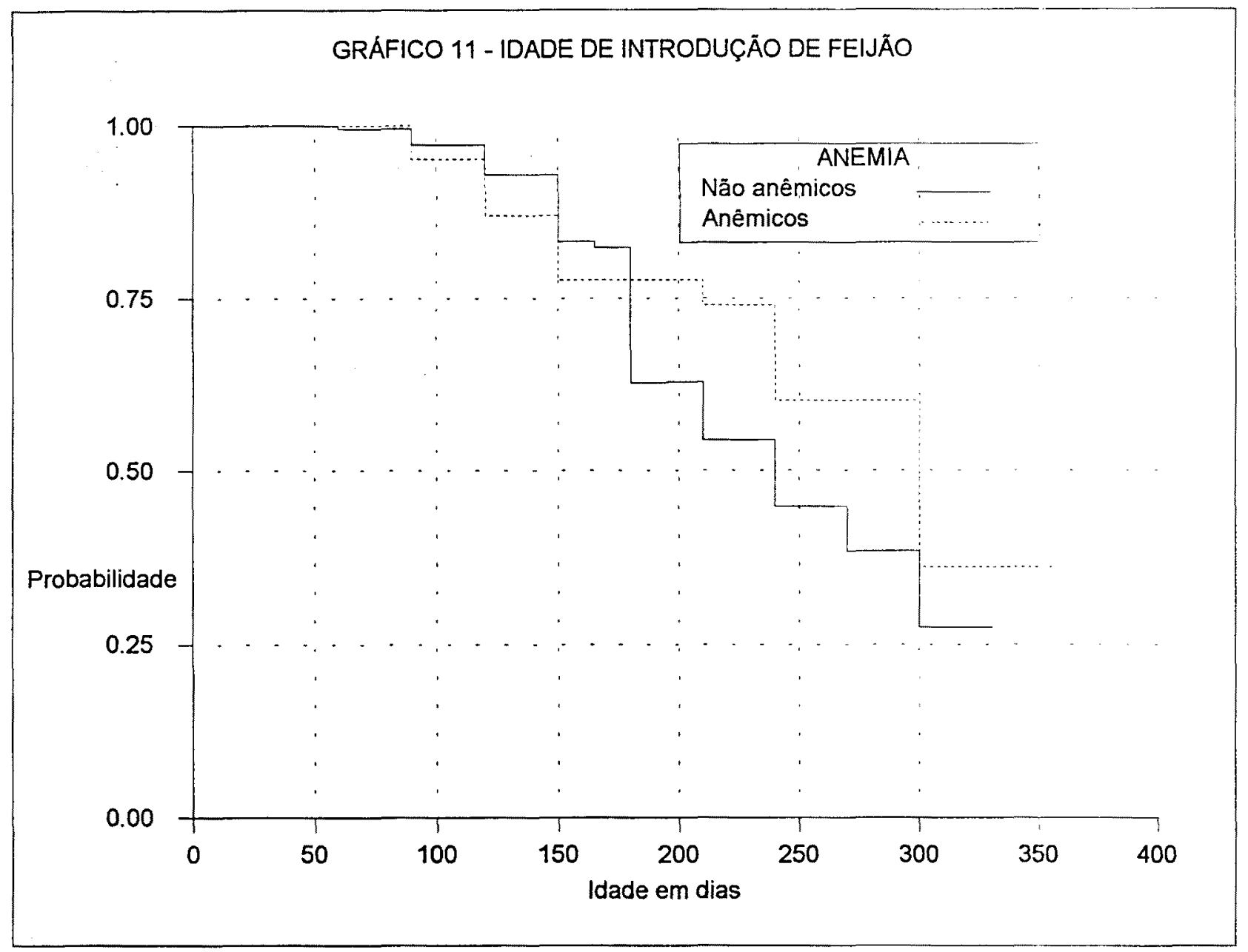

Em relação a hortaliças, foram consideradas apenas as de folhas devido ao seu maior conteúdo de ferro. Quanto à época de introdução na alimentação (gráfico 12), verifica-se que as curvas estão próximas, com idade mediana de introdução de 180 dias para os dois grupos $\left(\chi^{2}=0,12 \quad \mathrm{p}=0,73\right)$.

Chama atenção o fato de aproximadamente 25\% das crianças não anêmicas completarem 1 ano de vida sem terem recebido hortaliças em sua alimentação. 


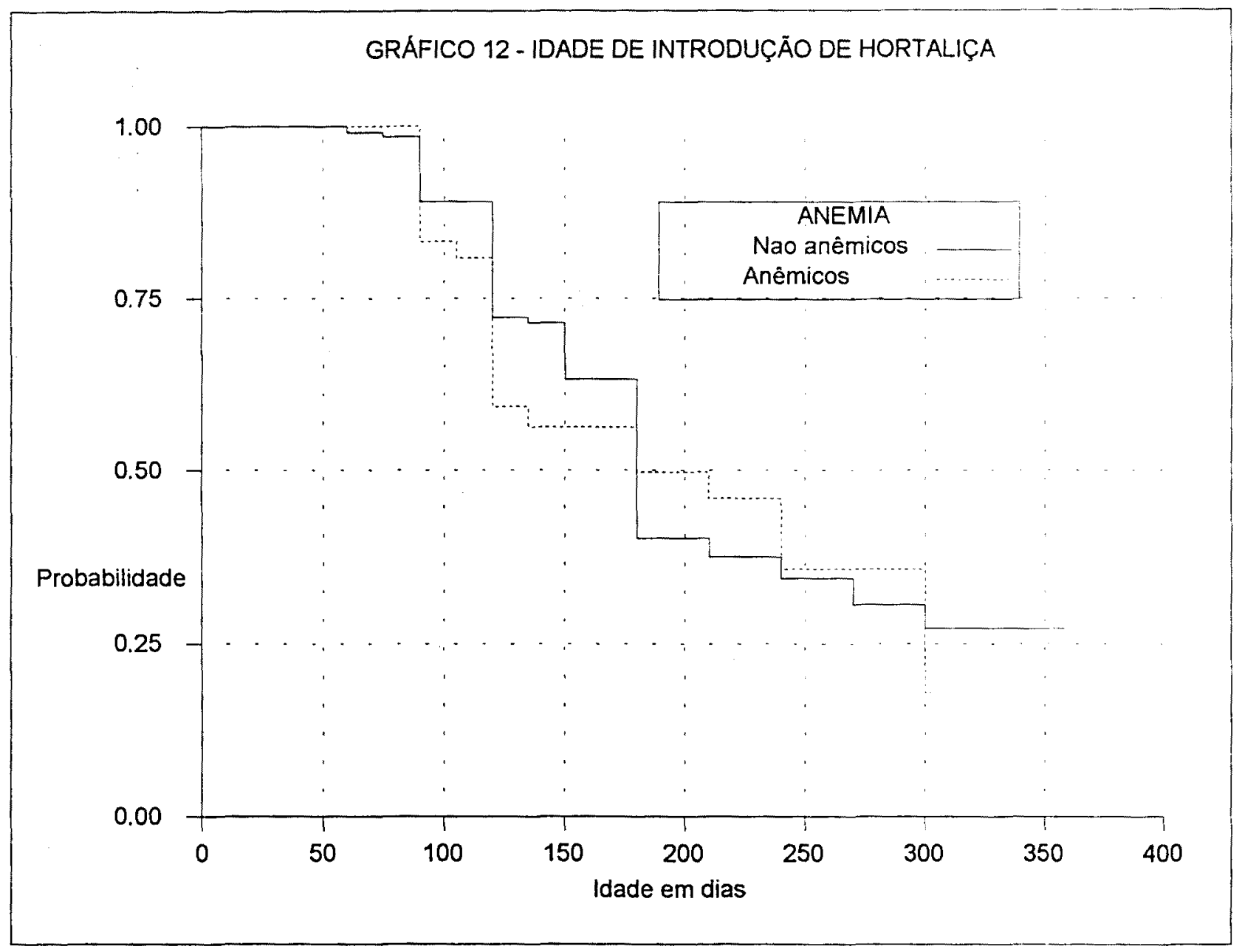

A gema de ovo foi estudada por ter sido tradicionalmente considerada como alimento fonte de ferro. Atualmente, sabe-se que o ovo, além de conter ferro de baixa biodisponibilidade, é inibidor de sua absorção, fato verificado graças a técnicas utilizadas para avaliação da absorção desse mineral19,61.

Em relação à introdução desse alimento (gráfico 13), nota-se que, a partir da idade de 180 dias, as duas curvas se distanciam sendo que, entre as crianças não anêmicas, o declínio da curva é mais rápido, mostrando introdução mais precoce de gema na alimentação. Essa diferença não é estatisticamente significante $\left(\chi^{2}=0,92 p=0,34\right)$. 


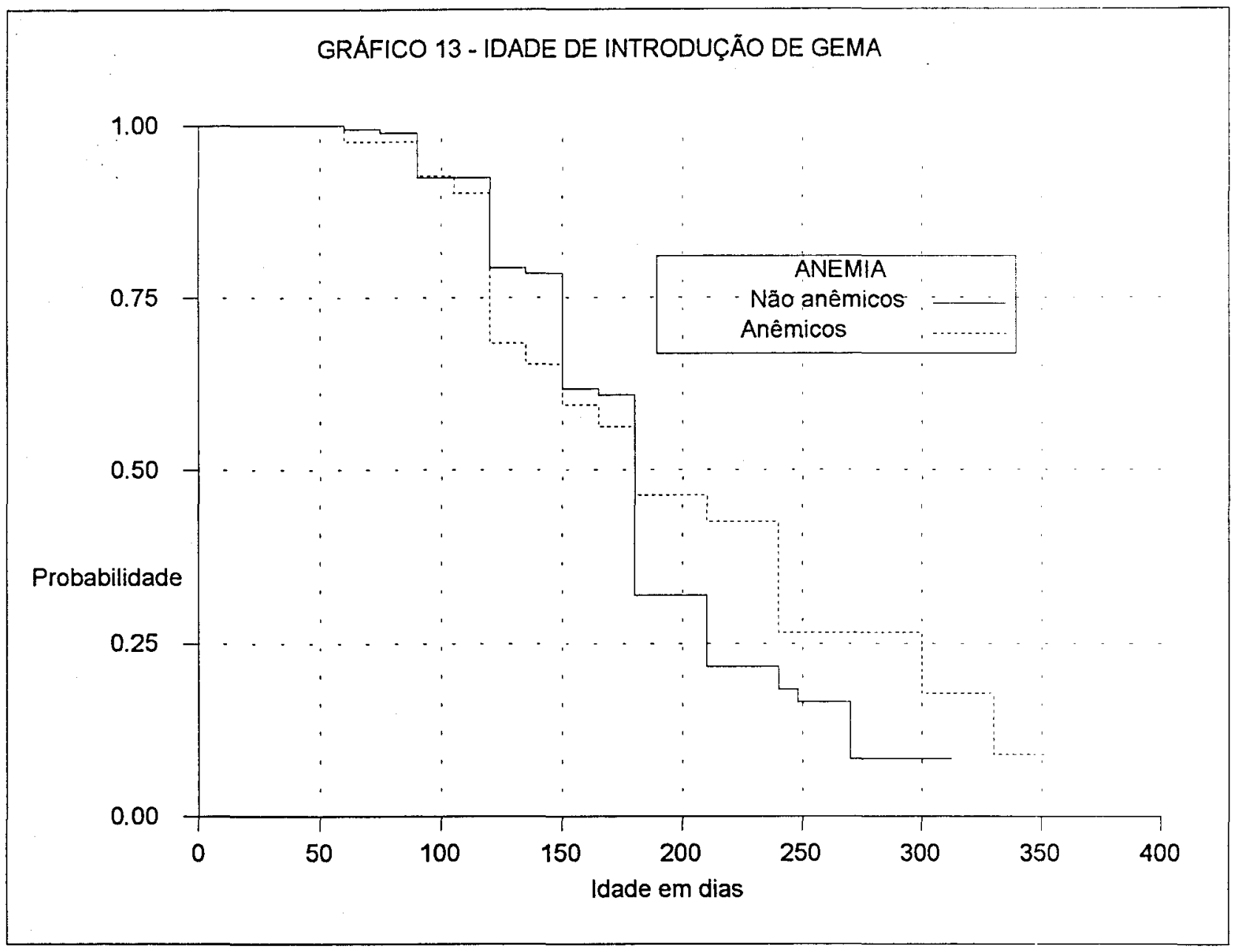

$\mathrm{Na}$ análise dos dados relativos à introdução dos diversos alimentos e de sua relação com a anemia, destacamos alguns pontos: as frutas e as carnes foram os alimentos introduzidos mais precocemente. Como foi verificado, a época de introdução de frutas na alimentação parece não ter relação com a anemia. É provável que isso tenha ocorrido pelo fato das frutas terem sido, geralmente, oferecidas às crianças isoladas da refeição de sal. Atualmente, a recomendação é para que elas façam parte da refeição como sobremesa, melhorando, pela presença de vitamina $C$, a biodisponibilidade do ferro não heme.

Com relação à carne, a preparação geralmente utilizada para a sua introdução na alimentação do lactente é a papa ou sopa, 
que deve ser preparada com legumes, verduras e um cereal, além da própria carne. Era de se esperar que as idades medianas de introdução de carne e hortaliças de folhas fossem próximas, o que, no entanto, não ocorreu. Provavelmente, isso seja devido ao fato da baixa utilização desse tipo de hortaliças. Legumes como cenoura, abóbora e chuchu - todos pobres em ferro - devem ter sido mais utilizados na preparação da sopa, conforme foi verificado, também, em outros estudos, que constataram a utilização, principalmente, de legumes, tubérculos e cereais 63,69 .

Outro fato a ser destacado é relacionado à introdução do feijão, que ocorreu mais tardiamente entre as crianças anêmicas, que foram privadas por mais tempo que as demais de um alimento importante no aporte de ferro, a partir do sexto mês de vida64. Vale destacar que a importância do feijão, como fonte de ferro, deve-se ao fato de ser um alimento consumido quase todos os dias, constituindo, com o arroz, a base da alimentação da maior parte de nossa população.

Considerando-se as idades medianas de introdução dos alimentos, nota-se que as crianças que estavam em aleitamento misto ou artificial introduziram leites aos 2 meses de idade, (gráfico 7), bem antes da introdução de carnes - 5 meses -, (gráfico 10) e/ou feijão - 8 a 10 meses - (gráfico 11), tendo permanecido, por um período razoavelmente longo, sem uma fonte de ferro na dieta, apesar do leite formulado que, conforme já discutido, deve ter sido utilizado por período de tempo muito curto. 
4.7. ANEMIA E FREQUUENCIA DE CONSUMO DE ALIMENTOS FONTES DE FERRO E/OU POTENCIADORES DE SUA ABSORÇÃO

A carne, o feijão e as hortaliças de folha foram considerados alimentos fontes de ferro; a fruta, pelo conteúdo de vitamina $C$, e a carne foram considerados alimentos potenciadores da absorção de ferro não heme.

As tabelas 28 a 31 mostram como se distribuem as crianças anêmicas e não anêmicas em relação à frequiência semanal de consumo desses alimentos.

TABELA 28 - NÚMERO E PORCENTAGEM DE CRIANÇAS, SEGUNDO FREQÜÊNCIA SEMANAL DE CONSUMO DE FRUTA NO ÚLTIMO MÊS E ANEMIA

\begin{tabular}{|c|c|c|c|c|c|c|}
\hline \multirow[b]{3}{*}{ ANEMIA } & \multicolumn{4}{|c|}{ FREQÜENNCIA DE CONSUMO } & & \\
\hline & \multicolumn{2}{|c|}{ DIÁRIA } & \multicolumn{2}{|c|}{ NÃO DIÁRIA } & \multicolumn{2}{|c|}{ TOTAL } \\
\hline & $\mathrm{N}$ & $\%$ & $\mathrm{~N}$ & $\%$ & $\mathrm{~N}$ & $\%$ \\
\hline SIM & 28 & 20,3 & 12 & 23,5 & 40 & 21,2 \\
\hline NÃO & 110 & 79,7 & 39 & 76,5 & 149 & 78,8 \\
\hline \multirow[t]{2}{*}{ TOTAL* } & 138 & 100 & 51 & 100 & 189 & 100 \\
\hline & ític & & $x^{2}$ & $p=$ & & \\
\hline
\end{tabular}


TABELA 29 - NÚMERO E PORCENTAGEM DE CRIANÇAS SEGUNDO FREQÜÊNCIA SEMANAL DE CONSUMO DE CARNE NO ÚLTIMO MÊS E ANEMIA

\begin{tabular}{|c|c|c|c|c|c|c|}
\hline \multirow{3}{*}{ ANEMIA } & \multicolumn{4}{|c|}{ FREQÜÊNCIA DE CONSUMO } & & \\
\hline & \multicolumn{2}{|c|}{ DIÁRIA } & \multicolumn{2}{|c|}{ NÃO DIÁRIA } & \multicolumn{2}{|c|}{ TOTAL } \\
\hline & $\mathrm{N}$ & $\%$ & $\mathrm{~N}$ & $\%$ & $\mathrm{~N}$ & $\%$ \\
\hline SIM & 20 & 21,3 & 9 & 20,0 & 29 & 20,9 \\
\hline $\mathrm{NÃO}$ & 74 & 78.7 & 36 & 80.0 & 110 & 79,1 \\
\hline \multirow[t]{2}{*}{ TOTAL* } & 94 & 100 & 45 & 100 & 139 & 100 \\
\hline & & & $\chi^{2}=0,13$ & $p=0,7189$ & & \\
\hline
\end{tabular}

TABELA 30 - NÚMERO E PORCENTAGEM DE CRIANÇAS SEGUNDO FREQÜÊNCIA SEMANAL DE CONSUMO DE FEIJÃO NO ÚLTIMO MÊS E ANEMIA

\begin{tabular}{|c|c|c|c|c|c|c|}
\hline \multirow{3}{*}{ ANEMIA } & \multicolumn{4}{|c|}{ FREQÜÊNCIA DE CONSUMO } & & \\
\hline & \multicolumn{2}{|c|}{ DIÁRIA } & \multicolumn{2}{|c|}{ NÃO DIÁRIA } & \multicolumn{2}{|c|}{ TOTAL } \\
\hline & $\mathrm{N}$ & $\%$ & $\mathrm{~N}$ & $\%$ & $\mathrm{~N}$ & $\%$ \\
\hline SIM & 10 & 21,7 & 3 & 10,7 & 13 & 17,6 \\
\hline NÃO & 36 & 78,3 & 25 & 89,3 & 61 & 82,4 \\
\hline \multirow[t]{2}{*}{ TOTAL* } & 46 & 100 & 28 & 100 & 74 & 100 \\
\hline & & & $\chi^{2}=1,05$ & $p=0,3057$ & & \\
\hline
\end{tabular}


TABELA 31 - NÚMERO E PORCENTAGEM DE CRIANÇAS SEGUNDO FREQÜÊNCIA SEMANAL DE CONSUMO DE HORTALIÇAS DE FOLHAS NO ÚLTIMO MÊS E ANEMIA

\begin{tabular}{|c|c|c|c|c|c|c|}
\hline \multirow{3}{*}{ ANEMIA } & \multicolumn{4}{|c|}{ FREQÜÊNCIA DE CONSUMO } & & \\
\hline & \multicolumn{2}{|c|}{ DIÁRIA } & \multicolumn{2}{|c|}{ NÃO DIÁRIA } & \multicolumn{2}{|c|}{ TOTAL } \\
\hline & $\mathrm{N}$ & $\%$ & $\mathrm{~N}$ & $\%$ & $\mathrm{~N}$ & $\%$ \\
\hline SIM & 18 & 26,5 & 6 & 16,2 & 24 & 22,9 \\
\hline NÃO & 50 & 73.5 & 31 & 83.8 & 81 & 77.1 \\
\hline TOTAL* & 68 & 100 & 37 & 100 & 103 & 100 \\
\hline & 0( & & $\chi^{2}=1,98$ & $\mathrm{p}=0,1595$ & & \\
\hline
\end{tabular}

Analisando-se a freqüência de consumo dos alimentos selecionados, verifica-se que mais da metade da população os consome diariamente, mostrando que, uma vez introduzidos na alimentação, seu consumo passa a ser frequiente.

Em relação à anemia, nota-se que a proporção de crianças anêmicas, entre as que consomem diariamente os referidos alimentos e as que não o fazem diariamente, é muito semelhante. Esse fato indica que não há associação entre a freqüência de consumo dos alimentos estudados e a anemia. Isso permite supor que, em média, a quantidade ingerida durante o mês talvez seja a mesma nos dois grupos, independentemente da freqüência. 
4.8. A ANEMIA E VARIÁVEIS SÓCIO-ECONÔMICAS : ESCOLARIDADE DO PAI E DA MÃE E RENDA FAMILIAR.

As caracteristicas sócio-econômicas da familia têm-se mostrado como um fator relevante para estudo das condições nutricionais e de saúde das crianças $11,24,31,51,60,68$.

Dois indicadores foram utilizados para avaliar o papel do nivel sócio-econômico na determinação da anemia: escolaridade do pai e da mãe e renda familiar. Os resultados obtidos são apresentados nos gráficos 14,15 e 16 .

- gráfico 14 mostra que pai sem escolaridade foi 0 grupo que apresentou a maior proporção de crianças anêmicas. A menor prevalência de anemia foi encontrada nas crianças filhas de pais com escolaridade baixa (curso primário incompleto). As diferenças encontradas não são estatisticamente significantes. 


\section{GRÁFICO 14 - PORCENTAGEM DE CRIANÇAS ANÊMICAS, SEGUNDO ESCOLARIDADE DO PAI}

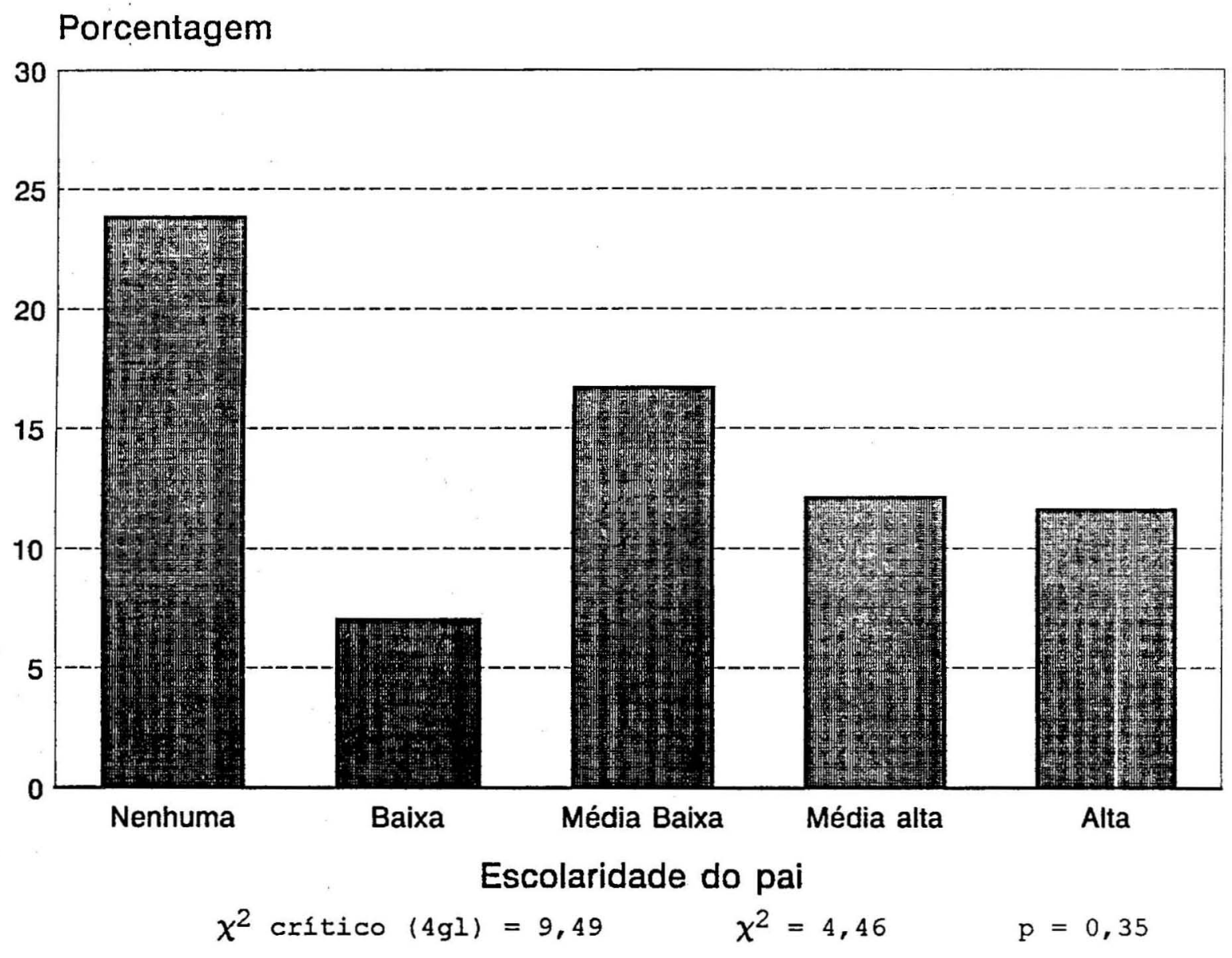

A tendência à diminuição da anemia com $\circ$ aumento da escolaridade materna pode ser observada no gráfico 15. Foge a essa tendência $\circ$ grupo de crianças filhas de mães com escolaridade média alta (curso ginasial completo e colegial incompleto), entre as quais a prevalência de anemia é maior que nas duas categorias anteriores. As diferenças verificadas não são estatisticamente significantes. 


\section{GRAFICO 15 - PORCENTAGEM DE CRIANÇAS ANÊMICAS, SEGUNDO ESCOLARIDADE DA MÄE}

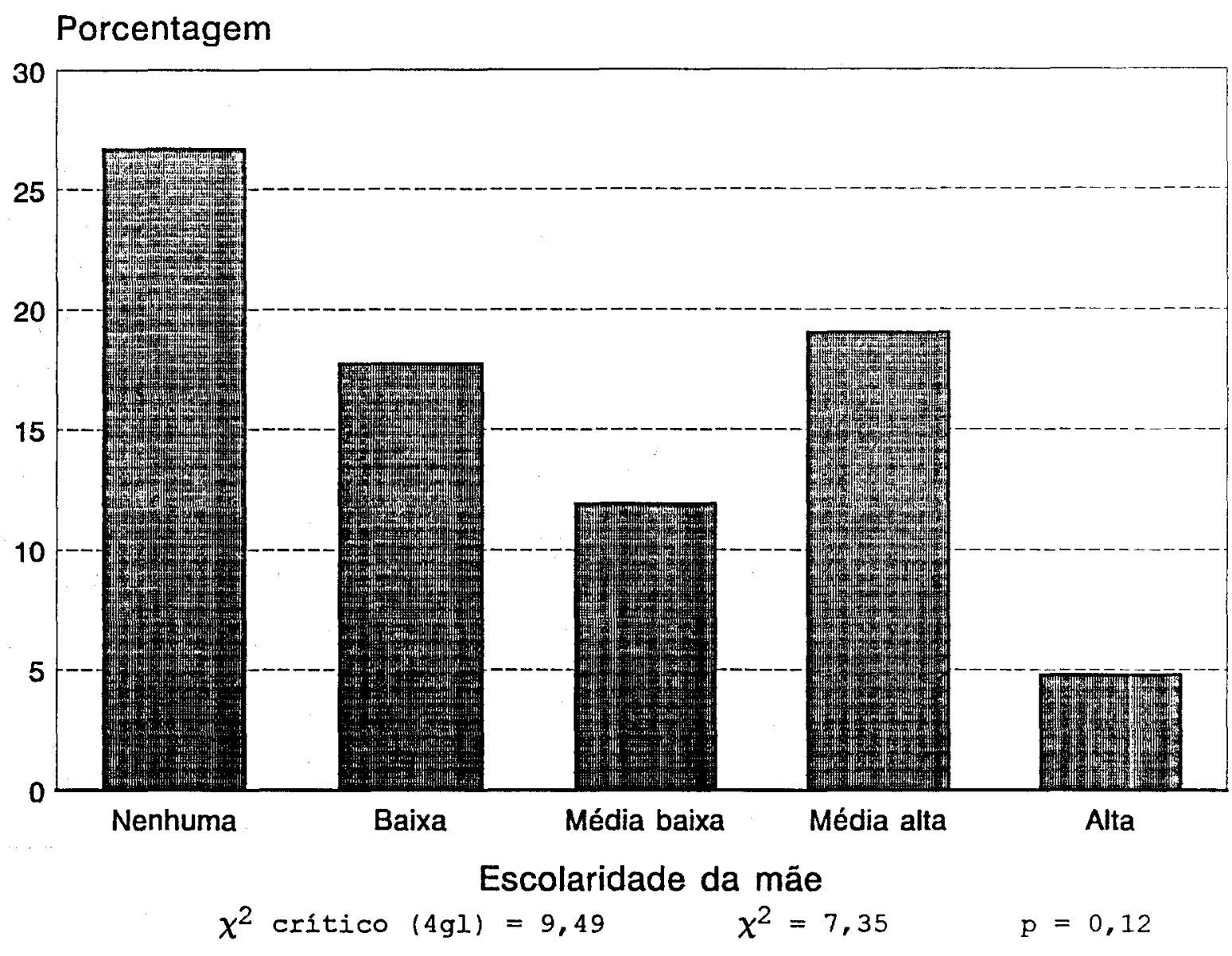

Quanto à renda familiar, o gráfico 16 mostra que as familias com oito ou mais salários mínimos são as que têm menor proporção de crianças anêmicas; o grupo de famílias com renda intermediária (4 a 7 salários mínimos) tem maior proporção de crianças anêmicas que o de renda mais baixa 10 a 3 salários mínimos). As diferenças verificadas não são estatisticamente significantes. 


\section{GRÁFICO 16 - PORCENTAGEM DE CRIANÇAS ANÊMICAS, SEGUNDO RENDA FAMILIAR}

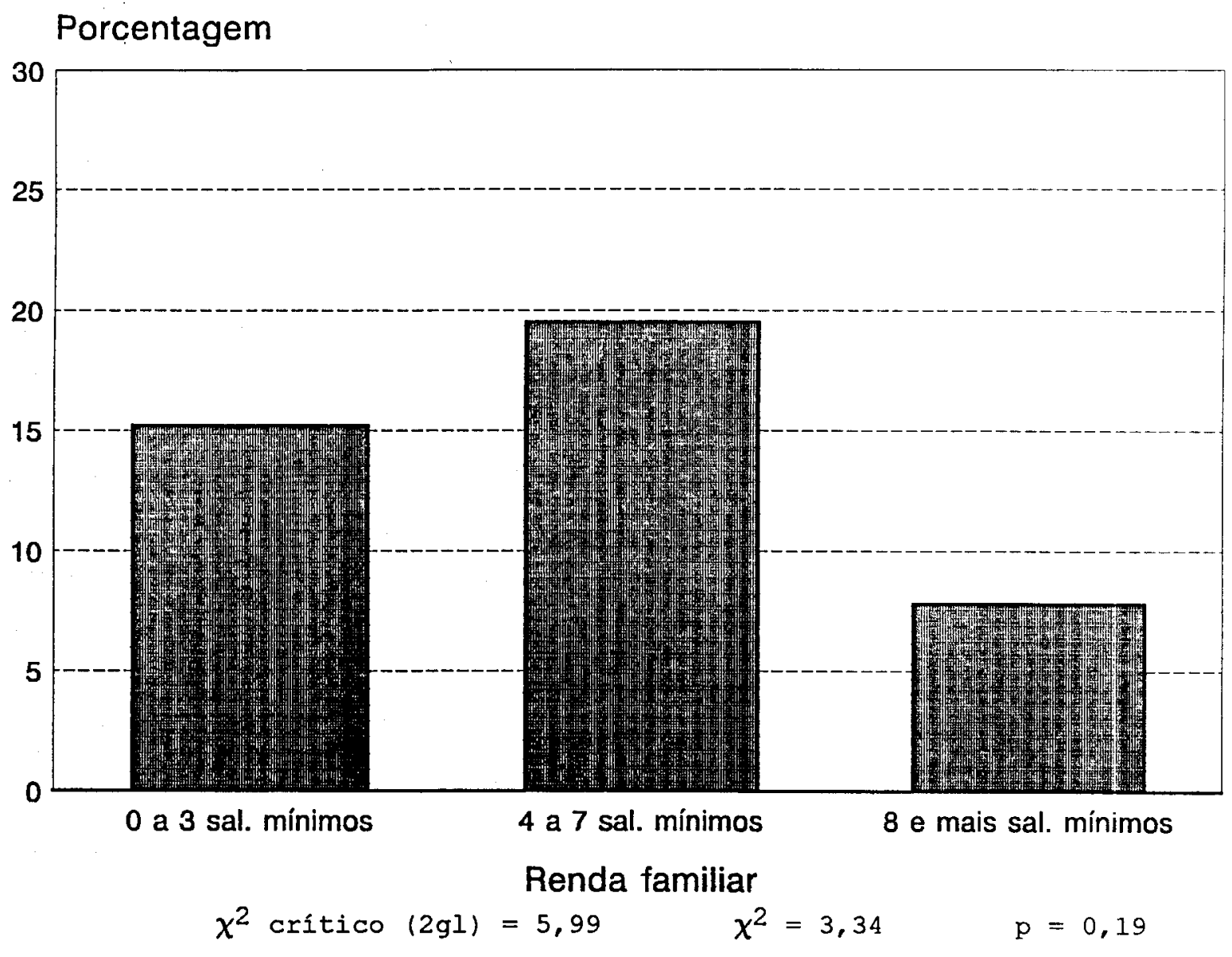

Não existe concordância entre os resultados obtidos em diferentes estudos que analisam as relações entre anemia e indicadores sociais.

Assim, no município de São Paulo, em 1984-85, foi verificada a associação entre anemia em crianças até 60 meses de idade, e nível sócio-econômico, obtido a partir da escolaridade do chefe da familia31. Em outro estudo, também no município de São Paulo, foi encontrada associação entre anemia e renda familiar somente em crianças maiores de 2 anos 50 . Em pesquisa realizada com populações de dois serviços de saúde, em Recife, verificaram-se 
prevalência de anemia nas categorias de maior renda; em outro, a prevalência foi elevada e semelhante em todas as faixas de renda. Freitas, em centro de saúde escola de Ribeirão Preto, não encontrou associação entre anemia e classe sociall6.

Provavelmente, a não associação estatística verificada no presente estudo possa ser justificada por ser a prática alimentar, especialmente no primeiro ano de vida, muito mais dependente de fatores culturais e da possibilidade de acesso à orientaça alimentar adequada que propriamente do seu custo, ou seja, da disponibilidade de recursos economicos. O grande valor atribuido ao leite, nessa fase da vida, muitas vezes em detrimento do consumo de outros alimentos, é um exemplo dessa afirmação. A dieta do lactente geralmente é monótona e com baixa densidade de ferro, independentemente das condições de vida da familia47,64,69. É provável, ainda, que os resultados tenham sido influenciados pelo pequeno número de crianças anêmicas, o que confere grande variabilidade à distribuição. 


\section{CONCLUSÕES}

Os resultados obtidos permitem as seguintes conclusões:

1. A proporção de crianças entre 3 e 6 meses de idade, em aleitamento materno exclusivo, foi 14,8\%, valor que caracteriza o desmame precoce.

2. As crianças em aleitamento artificial iniciaram o desmame com: leite formulado - 47,28; leite em pó integral $37,5 \%$; leite fluído - 15,3\%.

3. Entre as crianças que recebiam alimentos não lácteos, verificaram-se as seguintes idades médias de sua introdução: frutas - 3,4 meses; carnes - 4,6 meses; feijão - 5,8 meses; gema 5,2 meses; hortaliças de folha $-4,7$ meses.

4. Mais de $60 \%$ das crianças que já haviam introduzido alimentos não lácteos os receberam, com exceção da gema, diariamente no último mês. Afora feijão e hortaliças, essa prática foi confirmada pelo cardápio do dia anterior ao da entrevista.

5. A prevalência de anemia foi $8,7 \%$ para crianças com até 180 dias e 22,4\% para aquelas com mais de 180 dias. Sem considerar a idade, a prevalência foi 14,5\%, não havendo diferenças significantes entre as crianças dos quatro CSEs.

6. A distribuição dos valores de concentrações médias de hemoglobina mostra uma tendência à diminuição, que, se mantida, aumentará a prevalência da anemia no segundo ano de vida.

7. As concentrações de hemoglobina das crianças com baixo peso ao nascer diferiram daquelas da população total apenas nos dois primeiros meses de vida. 
8. As crianças anêmicas e não anêmicas não diferiram quanto à duração do aleitamento materno exclusivo e do aleitamento total. A duração mediana do exclusivo foi 60 dias para os dois grupos e do total foi 120 dias para ambos.

9. Verificou-se, entre as crianças com mais de 6 meses, que a introdução de outros leites antes de 4 meses é fator determinante da anemia. Encontraram-se 26,9\% de anêmicas entre esse grupo, contrastando com $8,6 \%$ entre as crianças em aleitamento materno.

10. A introdução de outros leites ocorreu igualmente até os três meses entre crianças anêmicas e não anêmicas. A partir dessa idade, a introdução foi mais precoce entre as crianças anêmicas.

11. O tipo de leite oferecido à criança (fluído, em pó integral, formulado), à época de sua introdução na dieta, não se mostrou associado ao aparecimento da anemia.

12. A época de introdução de alimentos não lácteos (frutas, carne, feijão, gema de ovo, hortaliças de folha) não diferiu entre crianças anêmicas e não anêmicas.

13. A frequiencia de consumo de alimentos fontes de ferro e de potenciadores da absorção do ferro não heme (carnes, feijão, frutas e hortaliças de folhas). foi semelhante entre crianças anêmicas e não anêmicas.

14. A prevalência da anemia não se associou com os indicadores sócio-econômicos: escolaridade e renda familiar. 


\section{CONSIDERAÇÕES FINAIS}

Dois aspectos observados no presente estudo merecem destaque: a prevalência da anemia (14,5\%), que pode ser considerada baixa, quando comparada com resultados encontrados em outras pesquisas, e a semelhança da prática alimentar das crianças anêmicas e não anêmicas.

A baixa prevalência pode ser explicada, em parte, por algumas caracteristicas da clientela dos serviços de saúde estudados. As condições sociais e econômicas da população atendida pelos CSEs, provavelmente melhores que as encontradas nas populações que constituem a demanda de outros serviços, bem como a axcelência do atendimento prestado pelos CSEs, devem ter influido nesse resultado.

Outro aspecto a ser mencionado é a valorização da puericultura por parte das mães cujas crianças são atendidas nesses Centros de Saúde. Ela está bastante voltada para os primeiros 6 meses de vida, influenciada, possivelmente, entre outros fatores, pelo calendário de vacinação. Diminui no segundo semestre de vida, sendo praticamente inexistente a partir de então. Esse comportamento, até certo ponto, condicionou a distribuição da amostra, formada na sua maior parte por crianças com menos de 6 meses. Para esse grupo de idade, a anemia se associa, principalmente, à prematuridade, devido ao baixo peso de nascimento, ou às intercorrências no período perinatal como hemorragias materno-fetais.

Na população estudada, a proporção de crianças com baixo peso ao nascer foi 9,8\%, não sendo verificada associação com a anemia. Todas as crianças haviam tido condições normais de nascimento, ficando afastada a ocorrência de hemorragias, conforme esperado, uma vez que a amostra foi constituida exclusivamente por crianças sadias. 
A ausência de associação entre dieta e anemia pode ser explicada por certas características da alimentação da criança no primeiro ano de vida. De modo geral, ela é monótona, por ser eminentemente láctea e por esse período ser uma fase de introdução de alimentos. As quantidades ingeridas desses alimentos são pequenas devido à limitada capacidade gástrica do lactente e, também, pela influência da aceitação dos mesmos. Além disso, a variedade oferecida é geralmente muito restrita.

- leite materno, no início da vida, é fundamental para fornecimento de ferro. A partir de 6 meses, as refeições de sal almoço e jantar - são aquelas em que os alimentos mais importantes na veiculação do ferro estão presentes (feijão e carne). o jantar (segunda refeição de sal) é introduzido na dieta ao redor de 9 meses e, portanto, pouco reflete na situação nutricional da criança até 1 ano. Na população estudada, verificou-se que o desmame é precoce e que, das 192 crianças que recebiam outros alimentos além do leite, $72,4 \%$ recebiam carne e apenas $39 \%$ comiam feijão.

Se, por um lado, não foi possivel distinguir anêmicos e não anêmicos pela alimentação, por outro, verificou-se que, entre as crianças menores de 6 meses, a proporção de anêmicos foi 8,7 , enquanto que, entre maiores de 6 meses a proporção foi de 22,4\%. Esse fato, aliado à tendência declinante da curva de concentrações médias de $\mathrm{Hb}$, observada no gráfico 1 , permite supor que a prevalência da anemia, no segundo ano de vida, será maior do que a encontrada no grupo de estudo.

Certamente a não associação observada entre prática alimentar e anemia não deve levar à conclusão de que a alimentação é fator de menor importância na etiologia dessa deficiência.

A história natural das deficiências nutricionais tem seu início na qualidade da dieta. Os sinais e/ou sintomas da doença ocorrem após um período mais ou menos longo de inadequação no consumo alimentar. 
- aparecimento da anemia não foge a esse modelo. Até aproximadamente 6 meses de vida a hemoglobina fetal oferece 0 ferro em quantidade suficiente. Nessa fase da vida é muito pequena a demanda por ferro exógeno. Porém, no segundo semestre de vida, o ferro da alimentação vai se tornando indispensável para suprir a necessidade do nutriente. A prática alimentar, nesse período, caso não atenda a essa necessidade levará a um risco crescente de anemia que poderá se manifestar, com todos os sinais e/ou sintomas, na fase de vida seguinte.

Em vista do exposto, reitera-se que a alimentação adequada no início da vida é fator fundamental na prevenção da anemia na infância. 


\section{REFERÊNCIAS BIBLIOGRÁFICAS}

1. ALVARENGA,A.T. et al. Indice de status sócio-econômico da familia da mulher grávida que frequenta o Centro de Saúde Geraldo de Paula Souza da Faculdade de Saúde Pública da Universidade de São Paulo.Rev.Saúde.Pública., 7: $351-67,1973$.

2. BRAULT-DUBUC, $M$. et al. Iron status of french-canadian children: a three year follow-up study.Hum.Nutr.Appl.Nutr. 37 A: $210-21,1983$.

3. BRESLOW, N. Statistical methods for censored survival data Environ.Health.Perspect., 32: 181-92, 1979.

4. BUTTE,N.F. et al. Macro and trace-mineral intakes of exclusively breast-fed infants. Am.J.Clin Nutr., 45: 42-8, 1987.

5. CALVO,E.B. et al. Estado nutricional de hierro en niños alimentados con formulas fortificadas de uso habitual. Rev.Hosp.Mun.Mat.Inf."Ramon Sarda". 5 (2): 9-15, 1985.

6. CALVO,E.B. et al. Iron status in exclusively breast-fedinfants. Pediatrics, 90: 375-9, 1992.

7. COMMITTEE ON NUTRITION OF THE AMERICAN ACADEMY OF PEDIATRICS. Vitamin and mineral supplement needs in normal children in the United States. Pediatrics, 66: 1015-21, 1980 .

8. DALLMAN,P.R. Progress in the prevention of iron deficiency in infants. Acta Paediatr.Scand.Suppl., (365): 28-37,1990. 
9. DeMAEYER, E.M. et al. Preventing and controlling iron deficiency anaemia through primary health care: a guide for health administrators and programme managers. Geneva, World Health Organization, 1989.

10. DeMAEYER,E.M. \& ADIELS-TEGMAN,M. The prevalence of anaemia in the world. World Health Stat., 38: 302-16, 1985.

11. DIMOND,H.J. \& ASHWORTH,A. Infant feeding practices in Kenia México and Malaysia. The rarity of the exclusively breast fed infant. Hum. Nutr.Appl.Nutr., 41 A: 51-64, 1985.

12. FILER,L.J. Iron needs during rapid growth and mental development. J. Pediatr., 117: 143-6, 1990.

13. FINCH, C.A. \& COOK, J.D. Iron deficiency. Am.J.Clin.Nutr., 39: $471-7,1984$.

14. FLORENTINO,R.F. \& GUIRRIEC,R.M. Incidência de la anemia nutricional en lactantes $y$ en niños. In: El hierro en la alimentación del lactante $y$ del niño. S.l.p., Nestlé Nutrition, 1984. p.26-8.

15. FRANCO,E. et al. Nutrición de hierro en lactantes mapuches alimentados con leche materna. (2 a etapa).Rev.Chil.Pediatr., 61: $248-52,1990$.

16. FREITAS,M.L.S. Estudo de algumas características biológicas e sociais, em relação à carência de ferro das crianças atendidas no Centro de Saúde-Escola, -Unidade Materno-infantil da Vila Tibério, Ribeirão Preto, 1987.Ribeirão Preto, 1990 [Dissertação de Mestrado - Faculdade de Medicina de Ribeirão Preto da USP].

17. GARN,S.M. et al. Maternal hematologic levels and pregnancy outcomes. Semin.Perinatol., 5: 155-62, 1981. 
18. GAY,J. et al. Profilaxis de la deficiencia de hierro en los niños de edad temprana:evaluacion biologica de una leche modificada. Rev.Cubana Aliment.Nutr., 4:43-54, 1990.

19. HALLBERG,L. Bioavailable nutrient density: a new concept applied in the interpretation of food iron absorption data Am.J.Clin.Nutr., 34:242-7, 1981.

20. HAMILL, P.V.V. et al. Physical growth: NCHS percentiles.Am. J.Clin.Nutr., 32: 607-29, 1979.

21. INTERNATIONAL NUTRITIONAL ANEMIA CONSULTATIVE GROUP. Guidelines for the eradication of iron deficiency anemia; report. Washington, DC., The Nutrition Foundation, 1977.

22. INTERNATIONAL NUTRITIONAL ANEMIA CONSULTATIVE GROUP. Measurements of iron status; report. Washington, DC., The Nutrition Foundation, 1985.

23. ISSLER,H. et al. Duração do aleitamento materno em uma área urbana de São Paulo, Brasil. Bol.Of.Sanit.Panam. 106:51322,1989 .

24. LEHMANN, E. et al Iron deficiency anaemia in 1-year-old children of disadvantaged families in Montreal. Can.Med. Assoc.J., 146: 1571-7, 1992.

25. LÖNNERDAL, B. Hierro y leche materna. In: El hierro en la alimentación del lactante y del niño. New York, Nestlé Nutrition, 1984. p.34-8.

26. LOZOF,B. et al. Long term developmental outcome of infants with iron deficiency. N.Engl.J.Med., 325:687-94, 1991. 
27. MCMILLAN, J.A. et al. Iron sufficiency in breast-fed infants and the avalability of iron from human milk. Pediatrics, 58: 686-91, 1976.

28. MINISTÉRIO DA SAÚDE, INSTITUTO NACIONAL DE ALIMENTAÇÃO E NUTRIÇÃO (INAN)/INSTITUTO NACIONAL DE ASSISTÊNCIA MÉDICA DA PREVIDENCIA SOCIAL (INSS). Aleitamento materno e orientaç̃o alimentar para o desmame. Brasilia, 1984.

29. MONTALTO,M.B.\&BENSON, J.D. Nutrient intakes of older infants: effect of different milk feedings. J.Am.Coll.Nutr., $\underline{5}: 331$ 4,1986 .

30. MONTEIRO,C.A. Saúde e nutrição das crianças de São Paulo. São Paulo, HUCITEC/EDUSP, 1988.

31. MONTEIRO,C.A. \& SZARFARC,S.C. Estudo das condições de saúde das crianças do Município de São Paulo, SP (Brasil), 1984/1985. V.Anemia. Rev.Saúde Pública, 21: 255-60, 1987.

32. MONTEIRO,C.A. et al. A distribuição do peso ao nascer no município de São Paulo, Brasil. Rev.Saúde Pública., 14:16172,1980 .

33. MURPHY,J.F. et al. Relation of haemoglobin levels in first and second trimesters to outcome of pregnancy. Lancet, 1: $992-5,1986$.

34. NEUTzLING,M.B. et al. Medindo o impacto da promoção do aleitamento materno em serviços de atenção primária à saúde em Pelotas, Rio Grande do Sul, Brasil. Cad.Saúde Pública, 9.:149-54, 1993 .

35. NÓBREGA, J.F. Antropometria do recém-nascido. São Paulo, Serviço de Informação Científica - Nestlé, 1989. 
36. NUTRITION COMMITTEE, CANADIAN PAEDIATRIC SOCIETY. Meeting the iron needs of infants and young children: an update. Can. Med.Assoc. J., 144:1451-4, 1991.

37. OSKI, F.A. \& NAIMAN, J.L. Hematologia do recém-nascido. $3^{a}$ ed. São Paulo. Ed. Manole. 1984.

38. OSKI,F.A. Is bovine milk a health hazard?. Pediatrics, 75 (Suppl.): 182-6, 1985.

39. OSKI, F.A. Whole cow milk feeding between 6 and 12 months of age? Go back to 1976. Pediatr.Rev., 12:187-9, 1990.

40. PASTEL,R.A. et al. Iron sufficiency with prolonged exclusive breast-feeding in peruvian infants. Clin.Pediatr., 20: $625-6,1981$.

41. PICCIANO,M.F. Oligoelementos en la leche materna y en la leches infantiles. In: Oligoelementos en la nutrición infantil. S.l.p., Nestlé Nutrition, 1986. p. 26-33.

42. RADRIGAN,M.E. et al. Alimentación en el primer año de vida. Rev.Chil.Pediatr., 60 (Suppl.1): 9-19, 1989.

43. RIOS,A.O. et al. Estudio de la incidencia de la carencia de hierro en niños menores de 2 años. Arch.Pediatr.Uruguay, 52: $120-9,1981$.

44. SALVIOLI, G.P. \& FALDELLA, G. Iron nutrition in infancy. Contrib. Infusion Ther.Clin. Nutr., 19: 50-60, 1988.

45. SALzano,A.C. et al. Anemias em crianças de dois serviços de Saúde de Recife, PE (Brasil). Rev.Saúde Pública, 19: 499507,1985 . 
46. SECRETARIA DE ESTADO DA SAÚdE. Centro de Apoio ao Desenvol vimento de Assistência Integral à Saúde (CADAIS) Manual de orientações para aleitamento materno, alimentação da criança no primeiro ano de vida, da gestante e do adolescente. São Paulo, 1992.

47. SICHIERI,R. et al. Relação entre dieta e ocorrência de anemia ferropriva em crianças. J.Pediatr., 64: 169-74 1988.

48. SIGULEM,D.M. Condições de saúde e nutrição de lactentes no municipio de São Paulo. São Paulo, 1981. [Tese de Doutorado-Escola Paulista de Medicina].

49. SIGULEM, D.M. \& TUDISCO,E.S. Aleitamento natural em diferentes classes de renda no município de São Paulo. Arch. Latinoam.Nutr., 30: 400-16, 1980 .

50. SIGULEM, D.M. et al. Anemia ferropriva no município de São Paulo. Rev.Saúde Pública, 12: 168-78, 1978.

51. SIGULEM,D.M. et al. Anemia nutricional e parasitose intestinal em menores de 5 anos. Rev.Paul.Med., 103:308-12, 1985.

52. SIIMES,M.A. El hierro en la alimentación de los niños de bajo peso al nacer. In: El hierro en la alimentación del lactante $y$ del niño. S.I.p., Nestlé Nutrition, 1984. p. 29-33.

53. SIIMES,M.A. et al. Exclusive breast-fedding for 9 months: risk of iron deficiency. J.Pediatr., 104: 196-9, 1984.

54. SILVA,R.C.R. Alimentos fortificados com ferro no combate à anemia ferropriva. São Paulo, 1991 [Relatório técnico apresentado ao CNPq] . 
55. SouZA, S.B. Tipo de aleitamento e morbidade. São Paulo, 1987. [Dissertação de Mestrado - Faculdade de Saúde Pública da USP] .

56. STEKEL, A. Necesidades de hierro en el lactante y el niño. In: El hierro en la alimentación del lactante $y$ del niño. S.1.p., Nestlé Nutrition, 1984. p. 7-10.

57. Stekel, A. Prevención de la deficiencia de hierro. In: El hierro en la alimentacion del lactante $y$ del niño. S.l.p., Nestlé Nutrition, 1984. p.49-53.

58. STEKEL, A.et al. Prevention of iron deficiency by milk fortification. II- A field trial with a full-fat acidified milk. Am.J.Clin.Nutr., 47: 265-9, 1988

59. STOCKMAN \& OSKI,F.A. Physiological anemia of infancy and the anemia of prematurity. Clin.Hematol., 7: 3-8, 1978.

60. SUBBULAKSHMI,G. \& UDIPI, S.A. Environmental factors, maternal attributes, and children's age at introduction of supplementary foods in rural and urban Maharashtra and Gujarat. Food Nutr. Bull., 12: 318-22, 1990.

61. SZARFARC, S.C. Densidade de ferro biodisponível em uma dieta habitual no Estado de São Paulo. Rev.Saúde Pública, 17: $290-6,1983$.

62. SZARFARC, S.C. Diagnóstico de deficiência de ferro na infância Rev.Saúde Pública, 19: 278-84, 1985.

63. SZAREARC, S.C. et al Consumo de ferro alimentar no primeiro ano de vida. Aliment.Nutr., 1: 38-42, 1980. 
64. SZARFARC, S.C. et al. Estudo das condicões de saúde das crianças do município de São Paulo, SP (Brasil), 1984/1985. X Consumo alimentar. Rev. Saúde Pública, 22:266-72, 1988.

65. SZARFARC,S.C. et al. Implantação e avaliação de Programa de controle da anemia na infância, através da rede básica de saúde.. São Paulo, 1991. [relatório técnico, FINEP].

66. TABOADA, H. Rol del hierro en la nutrición infantil; la Parte Rev.Chil.Pediatr., 54: 47-57, 1983.

67. TABOADA, H. Rol del hierro en la nutrición infantil. 2a Parte Rev.Chil.Pediatr., 54: 132-8, 1983.

68. TRUGO,N.M.F. et al. Folate, vitamin B12 and iron status of exclusively breast-fed and partially weaned brazilian infants from low-income families. Ecol. Food Nutr. ,25: 1991.

69. TUDISCO,E. et al. Alimentação no desmame em áreas periurbanas de quatro capitais brasileiras: resultados preliminares. J.Pediatr., 64:231-6, 1988 .

70. UNITED NATIONS DEVELOPMENT PROGRAMME. Human development report. New York. Oxford University Press, 1992.

71. VALLADA,E.P. et al. Anemia ferropriva em crianças da região laboratorial do Instituto Adolfo Lutz de Itapetininga-SP. Rev.Bras.Farm. , 68: 23-8, 1987.

72. VANNUCCHI, H. et al. Prevalência de anemias nutricionais no Brasil. Cad.Nutr., 4. 7-26, 1992. 
73. VIDAL, H. et al. Deficiência nutricional de hierro en niños de 6 meses a 2 años. Rev.Cubana Pediatr., 57:384-91,1985.

74. VIVANCO,G. Hemorragia feto-materna. Rev.Chil.Pediatr., 52: 496-501, 1981.

75. VYAS,D. \& CHANDRA,R.K. Consecuencias funcionales de la deficiencia de hierro. In: El hierro en la alimentacion del lactante y del niño. S.l.p., Nestlé Nutrition, 1984. p. 21-5.

76. WALTER, T. Infancy: mental and motor development. Am.J.Clin. Nutr., 50: 655-6, 1989.

77. WOODRUFF, C.W. et al. The role of fresh cow's milk in iron deficiency. Am.J.Dis.Child., 124:26-30, 1972. 


\section{ANEXO}

NOME :

No. DD REGISTRO:

DATA DA ENTREUISTA:

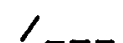

DATA DE NASCIMENTO:

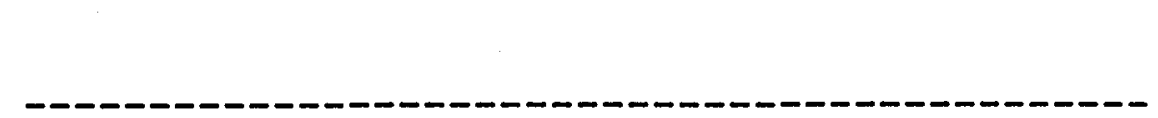

1) NO. DO QUESTIONÁRIO

CóDIGOS

2) CENTRO DE SAÚDE ?

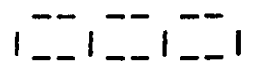

1) NO. DQ QUESTIQNARIO .

3) IDADE ? ...........

\section{CARACIERISIICAS DA FAMILIA}

4) QUE IDADE TEM O PAI E A MaE DA CRIANCA ?

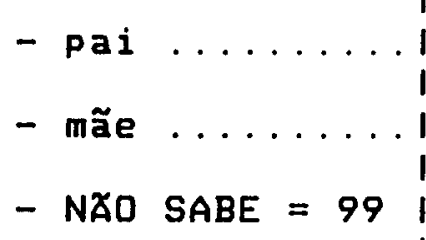

5) QUAL A ESCOLARIDADE DO PAI E DA MAE ?

$$
\begin{aligned}
& \text { pai mãe }
\end{aligned}
$$

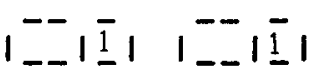

$$
\begin{aligned}
& |-| \underline{2}||_{-\infty}^{-}|\underline{2}| \\
& |-\bar{s}| 1_{-\infty}^{-\infty} \overline{3} \mid \\
& |-| \overline{4} \mid 1_{-\infty}^{-14} \\
& |--| \overline{5}||_{-\infty}^{-\mid \overline{5}} \mid \\
& |-\bar{\sigma}| 1_{-\infty}^{-\infty} \bar{\sigma} \mid
\end{aligned}
$$

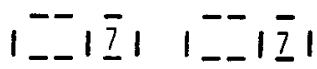

$$
\begin{aligned}
& \left.|-\overline{8}|\right|_{-\infty} ^{-1}|\overline{8}| \\
& \text { 1- } 1101 \quad 1_{--1101}^{--1}
\end{aligned}
$$

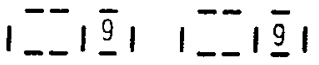


6) QUAL A OCUPACX̃O DO PAI E DA MÃE ?

- pai:

- mãe:

- NãO SABE $=99$

7) QUAL A RENDA TOTAL DA FAMILIA ?

- NXO SABE $=99$

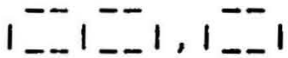

8) QUAL A DURACX̃O DA GESTACÃO ? (meses).

9) QUAL O PESO AO NASCER ? (gramas)

- NXO SABE $=9999$

10) QUAL O TIPO DE PARTO ?

OBS :

- normal

$1-\overline{1} \mid$

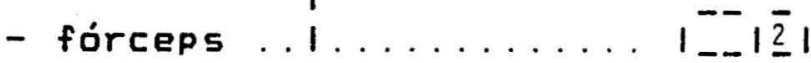

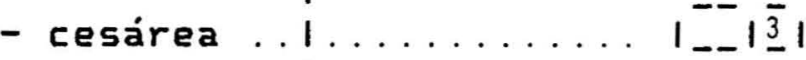

- não sabe $.1 \ldots \ldots \ldots \ldots \mathrm{I}_{--}^{--} \mathrm{I}_{-} \mathrm{I}$

11) QUAL O PESO ATUAL DA CRIANCA ? (gramas)... . .

12) QUAL A ALTURA ATUAL DA CRIANCA ? (cm)

13) A CRIANCA ESTA MAMANDO NO PEITO ATUALMENTE ?

Se acordo com a resposta, veja o No da questão a passar, para dar continuidade ao preenchimento, ou, se for o caso da primeira alternativa. encerrar a entrexista):

ENCERRE

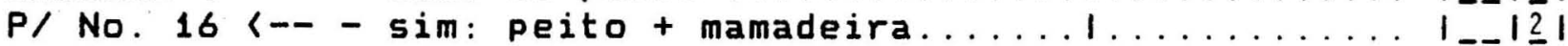

P/ No. 16 <-- sim: peito + mamadeira +1

P/ No. 35 (-- - sim: peito + outros alimentos

PRossiga 〈-.- - não: só mamadeira .............

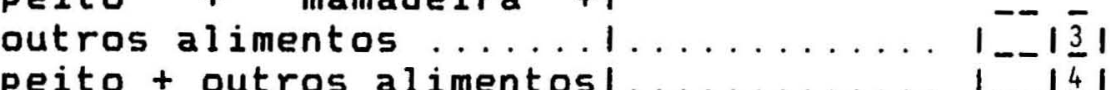

PROSSIGA (-- - não: mamadeira + outrosl

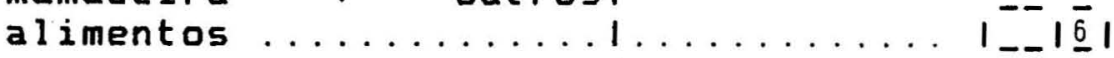


14) A SRA. ALGUMA UEZ AMAMENTOU A CRIANEA ? I

PASSE PARA A

- $\operatorname{sim}$

QUESTRO No. 16

- não

15) QUANTOS DIAS TINHA A CRIANCA QUANDO MAMOU NO PEITO PELA ULTIMA VEZ ?

- NÃO SABE OU NAO LEMBRA $=999$

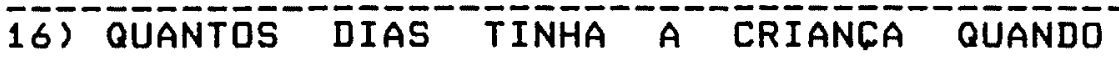
RECEBEU MAMADEIRA PELA PRIMEIRA VEZ ?

- NXO SABE OU NXO LEMBRA $=999$

17) QUUE LEITE A CRIANCA RECEBEU QUANDO । TOMOU MAMADEIRA PELA PRIMEIRA VEZ ?

- fluido

- em pó integral - QUAL ?

- em pó formulado - QUAL ?

- outro - QUAL ?

- não sabe ou não lembra

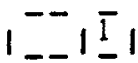

$1-\left.\right|^{2} \mid$

$1-1_{-1}^{\overline{3}} 1$

$|--| \overline{4} \mid$

$|--\overline{9}|$

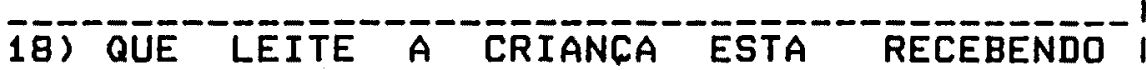
ATUALMENTE ?

- fluido

- em pó integral - QUAL ?

- em pó formulado - QUAL ?

- outro - QUAL ?

- fluido + em pó

- não sabe ou não lembra

19) QUANTAS VEZES A CRIANCA MAMA POR DIA ?

$1--\overline{1-n}$ 20) COMOA SRA. PREPARA O LEITE ?

- todas as mamadeiras do dia

$1-\overline{1} \mid \overline{1}$

- uma mamadeira de cada vez

$1-\overline{-}|\overline{2}|$

- outra maneira de preparar 
SE A CRIANCA RECEBE LEITE ELUIDO

21) DILUI COM ÁGUA?

- sim

I-- III

- não

$1-\overline{2} \mid$

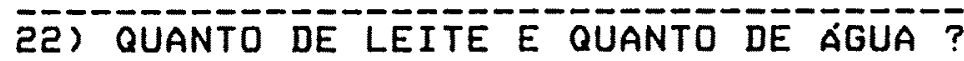

- leite $1 / 2$

$|-\overline{1}|$

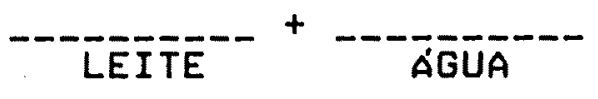

- leite $1 / 3$

$|-| \overline{2} \mid$

- integral

$\mid-\overline{3}_{-1}$

(3) COLOCA ACÚCAR OU OUTRO ADONCANTE ? SNO caso de colacar outro adofante que não o । afúcar, especifique qual)

- sim - QUAL ?

$1-\overline{1} \mid \overline{1}$

- não

$|--| \overline{2} \mid$

24) SE SIM, QUE QUANTIDADE COSTUMA COLOCAR ? I (gramas)

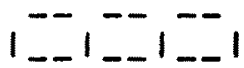

25) ENGROSSA D LEITE ?

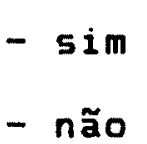

I--III

$1-\overline{1}|\overline{2}|$

26) SE SIM, QUAL D ESPESSANTE ?

- maizena

$|-\overline{1}|$

- farinha de arroz

$|-\overline{2}|$

- fubá

$1-\overline{1}^{-} \mid$

- aveia

$|--| \overline{4} \mid$

- farinha de trigo

$1--1 \overline{5} 1$

- outros - QUAIS ?

$|-\infty \overline{6}|$

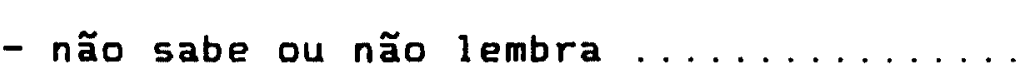

$1--|\overline{9}|$

27) QUE QUANTIDADE COSTUMA COLOCAR ? (gramas) I 


\section{SE A CRIANCA RECEBE LEITE EM Pó \\ INTEGRAL OU EORMULADO:}

28) QUE QUANTIDADE DE LEITE E DE ÁGUA COSTUMA COLOCAR ?

- gramas

- ml de água

হ̄) COLOCA ACÜCAR OU OUTRO ADONCANTE ? (NO caso de colocar outro adocante que não o afuicar, especifique qual)

$$
\begin{aligned}
& -\operatorname{sim} \text { - QUAL ? } \\
& \text { - não ....... }
\end{aligned}
$$

30) QUE QUANTIDADE COSTUMA COLOCAR ? (gramas)

31) ENGROSSA O LETTE ?

$$
\begin{aligned}
& \text { - } 5 \text { im } \\
& \text { - não }
\end{aligned}
$$$$
1-1
$$

32) SE SIM, QUAL O ESPESSANTE?

- maizena

$$
\begin{aligned}
& 1--\mid \underline{1} \\
& |--|^{-} \mid \\
& 1-\infty \overline{3} \mid \\
& |--| \overline{4} \mid \\
& |-|-|\overline{5}|
\end{aligned}
$$$$
\text { - aveia }
$$$$
\text { - farinha de trigo }
$$$$
\text { - outros - QUAIS? }
$$

- não sabe ou não lembra

33) QUE QUANTIDADE COSTUMA COLOCAR ?

(gramas)

34) QUAL A QUANTIDADE DE LEITE POR DIA ? (calcular)

SE NXO FOI INTRODUZIDO OUTRO ALIMENTO ALÉM DO LEITE, PASSE PARA A QUESTXQ No 53 E ENCERRE A ENTREUISTA

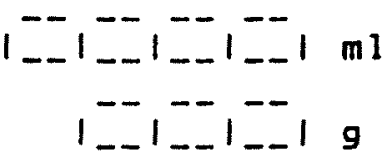


35) fruta (suco ou papa)

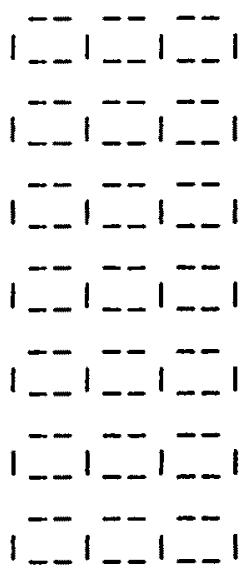

36) caldo de carne

37) carne

38) caldo de feijão

39) feijão (grão)

40) gema de ovo

41) hortalicas de folha

NO ÚLTIMO MÊS A SRA DEU OS ALIMENTOS

ABAIXO? QUAIS E COM QUE FREQUENCIA?

(ver relacão de códigos abaixo)

42) fruta (suco ou papa)

101

43) caldo de carne

44) carne

45) caldo de feijão

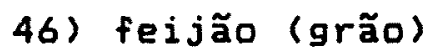

47) arroz

48) ovo

49) hortalicas de folha

50) pão ou bolacha

51) outros - QUAIS ?

Códigos:

-1 = diariamente

- 2 = quatro a seis vezes por semanal

- 3 = duas a três vezes por semana

- 4 = uma vez por semana

- 5 = menos de uma vez por semana

- $\theta$ = nunca

- 9 = กão sabe ou não lembra

5E) QUAANTAS REFEICÕES A 
ALIMENTO IDESJ. ILANC. IALM. ILANC. I JANT. ILANC.

I DURANTE A NOITE'। I (só para leite)

53) leite 1

\section{4) fruta (suco ou papa)}

55) caldo de carne

\section{6) carne}

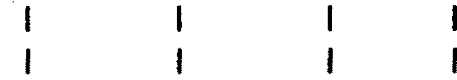

57) caldo de feijão

58) feijão (grão)

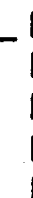

59) arroz

68) ovo

61) pão ou bolacha

62) hortalicas de folha

\section{3) outros}

a

